\title{
EL PRINCIPIO DE OBLIGATORIEDAD EN EL EJERCICIO DE LA ACCIÓN PENAL EN LOS PROCEDIMIENTOS JURISDICCIONALES BASADOS EN LA AUTOINCRIMINACIÓN
}

\author{
THE PRINCIPLE OF MANDATORY CRIMINAL PROSECUTION IN \\ RESPECT OF PROCEDURES BASED ON SELF-INCRIMINATION
}

\author{
Manuel Rodríguez Vega* \\ Octavio Pino Reyes ${ }^{* *}$
}

\begin{abstract}
RESUMEN: En este artículo se constata que la regulación nacional no contempla, respecto de los procedimientos basados en la autoincriminación, adecuados controles procesales sobre el obligatorio ejercicio de la acción penal conforme a la legalidad sustantiva que debe impulsar el Ministerio Público por imperativo legal, lo que deja como resultado, múltiples, extendidos e importantes espacios para el abandono o degradación de su ejercicio de manera discrecional, invirtiéndose con ello el modelo original de la codificación procesal, al desplazar, en el campo forense, la discrecionalidad a la obligatoriedad como regla en la persecución criminal.
\end{abstract}

Palabras clave: Discrecionalidad, principio de obligatoriedad, proceso penal.

ABSTRACT: This article states that the national regulation does not take into account, in respect of procedures based on self-incrimination, suitable procedural controls on the mandatory exercise of penal action according to the substantive law that should boost the prosecution by law, leaving as a result, multiple, large and important spaces to abandonment or degradation of its exercise of discretion, thus reversing the original model of procedural coding, as displaces in the forensic field, the discretion as to the binding rule in criminal prosecution.

Key words: Discretion, mandatory prosecution, criminal proceedings.

\section{INTRODUCCIÓN}

Como nos enseña Maier, el principio de legalidad, desde un punto de vista negativo, significa que ningún criterio de oportunidad - político-utilitario, por conveniencia práctica, económica, temporal, etc.- autoriza, en principio, a prescindir de la persecución penal frente a la noticia de la comisión de un hecho punible ${ }^{1}$. A este principio, por su mayor

\footnotetext{
Doctor en derecho, Universidad de Chile (2014); Magíster en Derecho, Universidad de Talca (2008); Licenciado en ciencias jurídicas y sociales, P. Universidad Católica de Chile (2001); profesor de la Escuela de Derecho, Universidad Católica Silva Henríquez, Dirección postal: General Jofré 462, Santiago; correo electrónico: mrodriguez@ucsh.cl.

" Magíster en derecho penal, Universidad de Chile (2012); Postítulo en Derechos Humanos, Universidad de Chile (2007); Licenciado en ciencias jurídicas y sociales, Universidad Nacional Andrés Bello (1995); profesor de la Escuela de Derecho, Universidad Católica Silva Henríquez. Dirección postal: General Jofré 462; correo electrónico: opino@ppj.cl.

1 Maier (1989) p. 548. v.t. Roxin (2000) p. 89, y Montero (2013) p. 29.
} 
precisión conceptual y neutralidad terminológica, nos referimos como obligatoriedad en el ejercicio de la acción penal ${ }^{2}$, sin desconocer que parte importante de la doctrina europeocontinental y nacional, suele denominarlo indistintamente como principio de legalidad o de legalidad procesal. Por similares motivos, también optamos en general por hablar de discrecionalidad para aludir al principio antagónico al recién mencionado, en desmedro del término oportunidad, pese a que esta denominación ha adquirido carta de naturaleza en nuestro medio jurídico.

En el sistema de justicia penal chileno este principio se consagra en el artículo 166, inciso $2^{\circ}$, del Código Procesal Penal (en adelante, CPP) y, de ese modo, la investigación se iniciará de oficio cuando el Ministerio Público (en adelante, MP) tomare conocimiento de la existencia de un hecho que revistiere caracteres de delito. Empero, este obligatorio ejercicio de la acción penal en la partida del procedimiento, se menoscaba cuando el MP fragmenta el hecho delictivo investigado y excluye de la pretensión procesal de la acusación, elementos fácticos que conducirían a una tipificación más gravosa del hecho principal, o constituirían circunstancias calificantes o agravantes del mismo. Si bien pudiera parecer que en tales supuestos la acción penal sigue ejerciéndose y, por tanto, no se ha descuidado el deber de perseguir el delito conocido, tal conclusión desatiende que su realización debe respetar los principios de legalidad procesal y objetividad que rigen las potestades y actuaciones del MP, así como la vigencia del principio de legalidad penal sustantivo y las garantías de la estricta jurisdiccionalidad y la exclusividad jurisdiccional en la aplicación del derecho penal ${ }^{3}$. Estos principios suponen que el órgano público de persecución no pueda discrecionalmente configurar los hechos que someterá al conocimiento y juzgamiento del tribunal, debiendo contener su requerimiento o acusación todos los elementos fácticos respecto de los que la investigación haya arrojado un fundamento serio para perseguir y que sean relevantes para la decisión jurisdiccional, todo ello salvo autorización legal en contrario. A los mismos reparos se expone una persecución que no se apega a la ley sustantiva al momento de subsumir los hechos sometidos a enjuiciamiento, si en el ejercicio de la acción penal el legislador no ha dotado al MP de discrecionalidad para postular la calificación jurídica del hecho.

Formas de incumplir el principio de obligatoriedad como las que hemos mencionado encuentran terreno fértil en el procedimiento simplificado de resolución inmediata y en el juicio abreviado ${ }^{4}$, al amparo de una regulación incompleta y confusa, carente de

\footnotetext{
2 Siguiendo con ello a Díez-Picazo (2000) p. 13. v.t. Conde-Pumpido (1989) pp. 290-291.

3 Del Río (2009b) pp. 79-80, menciona estos principios como limitaciones a las negociaciones llevadas a cabo en el marco del procedimiento abreviado, agregando la vigencia de la presunción de inocencia y la carga (formal) de la prueba sobre la acusación.

4 Podría también entenderse que se presentan en el procedimiento monitorio (artículo 392 CPP), ya que este implica la autoincriminación tácita por parte del imputado, en el caso que no manifestare de cualquier modo fehaciente su falta de conformidad con la imposición de multa o su monto. No obstante, lo anterior dependerá de la voluntad del propio imputado y no del fruto de una negociación alcanzada con el MP (lo que es objeto de análisis de este artículo), la que se producirá solo en el caso que el imputado reclame el monitorio, aplicándose en dicho caso las normas del procedimiento simplificado, que analizaremos pronto. Reconocemos en todo caso, que no es infrecuente que ante el reclamo por parte del imputado respecto del procedimiento monitorio, el MP opte por aplicar el principio de oportunidad (artículo $170 \mathrm{CPP}$ ), no existiendo negociación alguna entre las partes.
} 
los controles judiciales necesarios para ponerle atajo. En estos procedimientos, el MP el imputado y su defensa, disponen sobre el desarrollo del proceso -consenso sobre el rito procedimental-, pues excluyen el juicio oral como su etapa final y regular, mutándola por un juzgamiento en base a la confesión judicial y el examen de los registros de la instrucción. Sin embargo, la disposición de las partes no se ha frenado en el ámbito adjetivo, pues la imprevisión legislativa y la lagunosa regulación de esos procedimientos, ha dado pie a los operadores para disponer también del derecho penal material (delito-pena) mediante pactos sobre el contenido de la acusación -consenso sobre el mérito del proceso-.

En cuanto a ambos tipos de consenso, recaídos sobre el rito procedimental y sobre el mérito fáctico y jurídico del proceso, Del Río 5 sentencia que dentro del ordenamiento chileno no cabe admitir sino una aplicación del principio de consenso de las partes respecto del primero, pero no sobre este último, salvo de manera restringidísima en cuanto haya reconocimiento legal de efectos limitadores del marco punitivo, puntualizando más tarde el mismo autor ${ }^{6}$ que podría darse cabida a formas de consenso razonables, tasadas y controladas que no comprometan la esencia de la jurisdicción. Esta visión restrictiva sobre el alcance de los consensos que pueden lograrse al interior del proceso penal, concuerda con el Mensaje con que se acompañó el Proyecto de CPP, al señalarse ahí que "se propone la creación de algunos procedimientos simplificados en que por la vía de acuerdos entre todos los intervinientes o de algunos de ellos, se supriman etapas del curso ordinario del procedimiento de modo que se permita alcanzar una solución rápida del caso por medio de una sentencia definitiva, siempre que ello resulte posible sin vulnerar los valores que el sistema busca proteger".

\section{RETRIBUCIÓN PREMIAL POR RENUNCIA AL JUICIO ORAL}

Mientras el procedimiento inquisitivo en los sistemas de justicia continentales consistió en la mera verificación pública del contenido del dossier de la investigación preliminar, el aparato de justicia criminal tenía escaso interés de negociar beneficios con el acusado, pues no había mayor incertidumbre acerca de la decisión que tomarían los jueces profesionales en este remedo de juicio ${ }^{7}$. Este escenario cambió radicalmente en Europa continental, así como en Chile, con el arribo de un juicio oral, público y contradictorio, pues la incertidumbre de un resultado exitoso para el Estado persecutor -representado por la Fiscalía-, ante la dificultad y onerosidad de llevar a estrado la prueba necesaria para superar exigentes estándares surgidos a la luz del enérgico desarrollo de los derechos humanos que tuvo lugar con posterioridad a la Segunda Guerra Mundial, hizo necesario admitir o incorporar mecanismos procesales de consenso que evitaran que la actuación de la ley penal se viera frustrada del todo.

\footnotetext{
5 Del Río (2009b) p. 31.

6 Del Río (2010) p. 356.

7 v. DAmaska (2010) p. 86. Respecto de la situación en Chile en los procedimiento seguidos bajo la vigencia del Código de Procedimiento Penal de 1906, v. Piedrabuena (2000) p. 14, y Duce y Riego (2002) p. 93.
} 
Pero sin duda que tras esta tendencia a la composición también podría ocultarse el temor de la Fiscalía de que el juicio oral deje en evidencia investigaciones mal conducidas. Efectivamente, cuando un país tiene un sistema procesal sólido, el acusado que ha cometido un delito grave tiene la seguridad de que si existen suficientes pruebas incriminatorias, con toda probabilidad resultará condenado, situación en la que tiene sentido llegar a un acuerdo en el que obtenga una sentencia algo más benévola, y por su lado, el Estado evite un proceso largo y complejo, difícil de sustentar dados los limitados recursos con que cuentan los tribunales en la mayor parte de los países. En cambio, cuando un país tiene un sistema procesal débil, se ve abocado a dar por bueno cualquier tipo de acuerdo extraprocesal con tal de evitar ir a juicio ${ }^{8}$.

Pues bien, por estas y otras razones, este principio de consenso, tradicional de los sistemas del common law, se ha propagado hoy en día por los ordenamientos europeo-continentales así como latinoamericanos, en respuesta a la necesidad de atender un mayor número de procesos ingresados al sistema de justicia criminal, de manera tal que se ha llegado a concluir que el proceso adjudicativo completo, es decir, el juicio oral, está en todas partes en decadencia?.

Huelga anotar que estas fórmulas procesales paccionadas fueron recibidas también en nuestro ordenamiento en las modalidades arriba reseñadas, pero para incentivar al imputado y su defensa a utilizarlas se hizo imperioso premiar su renuncia al derecho de defensa en juicio oral a través de una atenuación de la pena en relación a la que se expondría de ser condenado en el procedimiento ordinario. Si la Fiscalía no efectuara esta dimisión, no habría un incentivo real para la abstención del acusado de ir al juicio oral, instancia donde la posibilidad de una absolución por incomparecencia de testigos, retractación o desinterés de la víctima, o los más variopinto motivos, es altamente probable.

Por otra parte, la imprevisión legislativa para dotar de un adecuado instrumental a los jueces para disuadir, evitar y corregir abusos en la reducción de la pretensión procesal del MP, ha derivado en las exageradas menguas que pueden alcanzar las sanciones penales resultantes de estas negociaciones entre Fiscal-imputado, cuya nimiedad no contribuye de modo alguno a los fines que suelen atribuirse a la pena $\operatorname{criminal}^{10}$. Lo anterior, pareciera demostrar que el persecutor penal en realidad muchas veces persigue por su intermedio solo el etiquetaje del hechor - a modo de labeling theory $-{ }^{11}$ de manera que aun cuando la pena, por lo exigua de la misma, no sirva como expresión de reproche ni cumpla ningún fin disuasivo ni preventivo, permita sin embargo el etiquetaje social del autor como desviado. Con ello, en el próximo proceso penal a que se verá enfrentado este hechor -pues el Fiscal, atendido el nulo efecto que tendrá la pena ahora impuesta, ya asume la futura reincidencia como un evento casi cierto-, este ya no será considerado como primerizo, y por lo tanto la

\footnotetext{
8 Pizzi (2004) p. 209.

9 Damaska (2010) p. 82.

10 Sobre las aprensiones manifestadas por algunos parlamentarios durante la discusión de la modificación del inciso $2^{\circ}$ del artículo 395 CPP original, v. Segundo Informe de la Comisión de Constitución, Legislación, Justicia y Reglamento del Senado de Chile (en adelante, Comisión del Senado) correspondiente a la tramitación de la Ley No 20.074.

11 Becker (2009). Sobre labeling approach, v. HaSSEMER (1984) pp. 81-84.
} 
pena se exasperará por operación de las normas agravatorias fundadas en la reincidencia, o al menos será más severa, al privarle el acceso a una pena sustitutiva de la Ley No 18.216. En otras palabras, la lógica de esta política criminal de actuación es que la verdadera sanción por el primer hecho delictual será la agravación de la sanción que su autor sufrirá por el segundo ilícito que se asume cometerá en el futuro ${ }^{12}$.

\section{INCENTIVO PUNITIVO EN EL JUICIO ABREVIADO}

El inciso $3^{\circ}$ del artículo 407 del CPP prescribe que: "Si se hubiere deducido acusación, el fiscal y el acusador particular podrán modificarla según las reglas generales, así como la pena requerida, con el fin de permitir la tramitación del caso conforme a las reglas de este Título. Para estos efectos, la aceptación de los hechos a que se refiere el inciso segundo del artículo 406 podrá ser considerada por el fiscal como suficiente para estimar que concurre la circunstancia atenuante del artículo 11, No 9, del Código Penal, sin perjuicio de las demás reglas que fueren aplicables para la determinación de la pena”.

Destaquemos inmediatamente que el texto transcrito excluye la modificación discrecional de la pena pretendida por el acusador y sujeta la realización de esta a las reglas generales, con lo que pareciera hacer una remisión al párrafo IV, del título III del libro I del $\mathrm{CP}$, que gobierna la determinación legal y judicial de las penas, acotando con ello el campo de acción de la negociación al juego de la operatividad de dichos preceptos. Confirma este aserto, el que se haya autorizado al Fiscal para considerar la aceptación de hechos que el acusado realiza en el juicio abreviado, como suficiente para la concurrencia de la circunstancia atenuante del artículo 11 No 9 del CP, "sin perjuicio de las demás reglas que fueren aplicables para la determinación de la pena”, lo que da cuenta que el interés del legislador fue que dicha atenuante operara en conjunto con las otras circunstancias modificatorias que concurrieren, en la forma prevista en el párrafo IV del título III, y no según el arbitrio del MP. En la línea de lo que se viene argumentando, durante la discusión parlamentaria se tuvo presente que, por "la amplitud de las escalas de penas que contempla nuestro Código Penal, el fiscal tiene una posibilidad amplia para ofrecer pena, incluyendo el balance de las atenuantes y agravantes"13.

Más complejo es discernir si esta modificación de la acusación y de la pena realizada por el Fiscal puede consistir en algo más, y en su caso, en qué. En esta materia la doctrina ha entendido principalmente que la modificación de la acusación puede consistir en la retirada de hechos - v.gr. retirada del actuar sorpresivo en la sustracción-cuando, por la insuficiencia de antecedentes de investigación se vislumbra como improbable probar en el juicio el hecho punible tal como se plantea en la acusación ${ }^{14}$.

\footnotetext{
12 Sobre la incidencia del incremento sostenido de los procedimientos basados en la autoincriminación que aquí se estudian en la punición efectiva de la eventual segunda condena (reincidencia) v. SALINERo (2012) p. 132.

13 Segundo Informe de la Comisión de del Senado. Al respecto, v. Del Río (2009b) pp. 44-45; y, Maturana y Montero (2010) T. II, p. 1063.

14 v. Mera (2004) p. 253; Horvitz (2005) T. II, p. 522; y, Del Río (2009b) p. 75. En la jurisprudencia, v. Ministerio Público con Bustamante (2009); y Ministerio Público con Madariaga (2009).
} 
En lo que nos interesa, si la bajada de material fáctico de la acusación -ya sea en relación a la primera acusación o a la formalización de la investigación ${ }^{15}$-, obedece auténticamente a una tardía advertencia por el Fiscal de la debilidad de los antecedentes reunidos para acreditarlo, sin duda que tal actuación se ajusta al principio de objetividad que rige su actividad y aun sin la autorización del artículo 407 en comento, podría haberse ejecutado. Ahora bien, el verdadero problema de esta tesis es que deja amplio margen al abusivo ingenio del overcharging, como es conocida esta operación en el derecho estadounidense, con el que se aborda dos distintos problemas: a) horizontal overcharging, esto es, la actitud del MP de multiplicar sin razón alguna el número de acusaciones contra un único acusado; $y, b$ ) vertical overcharging, en este caso se acusa al defendant con un solo cargo, pero en un grado más alto del que las circunstancias del caso parecen justificar ${ }^{16}$. El overcharging generalmente va de la mano con lo que se ha denominado como bluffing, esto es, tratar de hacer aparecer la evidencia de una acusación muy sólida, cuando en la realidad no lo es tanto, ello con el propósito de dar la impresión de que en el juicio se obtendrá una sentencia condenatoria segura, de modo que el acusado crea como conveniente cualquier pacto que ofrezca la acusación por mínima que sea la rebaja ofrecida ${ }^{17}$.

Engarzando todo lo dicho arriba, aceptar para nuestro ordenamiento que la retirada de material fáctico de la acusación responda a las debilidades probatorias para acreditarlo, implica dispensar al MP de su deber de objetividad (artículos 83 de la CPR, $1^{\circ}$ y $3^{\circ}$ de la Ley Orgánica Constitucional del MP y 77 del CPP), por el cual debe acusar "velando únicamente por la correcta aplicación de la ley", y por tanto, solo respecto de hechos suficientemente justificados durante la investigación y que podrá probar en el juicio. De otro modo, se incentivaría al MP a abultar los hechos de la acusación, no obstante saber que se carecerá de prueba para acreditarlos en el juicio oral, con el único objeto de autogenerarse un margen para regatear con el imputado, quien renunciaría inútilmente al juicio oral, pues ante la falta de prueba solo se habría acreditado en dicha instancia el mismo suceso que se terminó aceptando en el juicio abreviado ${ }^{18}$.

Igual motivo de queja debe dirigirse contra la mutación de la calificación jurídica del hecho imputado en la acusación $-v$.gr. el tránsito de hurto consumado a frustrado ${ }^{19}-$, de suerte que el encuadre jurídico del material fáctico de la acusación no puede perderse de ese norte e inflarse por el MP precaviendo las utilidades que ello le reportará en una eventual negociación, y por otro lado, confiándose que de no prosperar esta, será corregida por el tribunal en su fallo.

\footnotetext{
15 Aunque estas modificaciones se proponen por la cátedra en relación a una primera acusación ya formulada por escrito (artículo 407, inciso $3^{\circ}$, del CPP), lo cierto es que lo que se razonará igualmente será válido respecto de una primera acusación formulada verbalmente en la audiencia convocada al efecto (artículo 407, inciso $2^{\circ}$, del CPP), caso en el cual la modificación se efectuará en relación a la formalización de investigación previa.

16 Alschuler (1968-69) pp. 85-86. v.t. Mcdonald (1986-87) p. 203, n. 2; Rodríguez (1997) p. 68; y, Pizzi (2004) p. 213.

17 v.t. Rodríguez (1997) p. 69.

18 v. SCHÜNEMANn (2002) p. 301, n. 26.

19 Lo comentado se refleja en García con Carrasco (2013).
} 
De asentarse la tesis enunciada -retiro del material fáctico no suficientemente acreditado de la acusación - en la realidad del foro, prontamente las defensas y los imputados advertirán que ninguna ventaja representa para ellos la modificación de la acusación realizada por el Fiscal, pues simplemente ha ajustado la acusación a lo que podría probar en el juicio oral, por lo que nada perderían entonces insistiendo con dicha instancia ${ }^{20}$.

Entonces, si se acepta que la acusación no debe contener sino los hechos y la calificación sobre los que la investigación "proporciona fundamento serio para el enjuiciamiento", cuando el Fiscal en medio de una negociación con el imputado ajusta la acusación a dicho parámetro, en verdad no la ha modificado en uso de su discrecionalidad, sino más bien la ha corregido en cumplimiento de su deber de actuar con objetividad y dar correcta aplicación a la ley. Y situados en este contexto, pareciera que lo reflexionado permitiría concluir que si el legislador autoriza al MP, no obstante encontrarse ya agotada y cerrada la investigación y presentada una acusación respetuosa del principio de objetividad, a modificar esta más allá de las secuelas de la incorporación de la mitigante del artículo 11 No 9 del CP, esa modificación obedecerá al resultado de una alteración paccionada de los hechos principales o accesorios acreditados durante la investigación y/o de su calificación jurídica ${ }^{21}$. Y es esta difusa habilitación legal la que ha dado pie a formulaciones fácticas y jurídicas discrecionalmente recortadas y enmendadas por parte de la Fiscalía, no obstante constituir un tipo de discrecionalidad positiva no reconocida por nuestro ordenamiento ${ }^{22}$.

\section{InCENTIVO PUNITIVO EN EL PROCEDIMIENTO SIMPLIFICADO DE RESOLUCIÓN INMEDIATA}

Comencemos trayendo a colación el texto del inciso $1^{\circ}$ del artículo 395 del CPP: "Una vez efectuado lo prescrito en el artículo anterior, el tribunal preguntará al imputado si admitiere responsabilidad en los hechos contenidos en el requerimiento o si, por el contrario, solicitare la realización de la audiencia. Para los efectos de lo dispuesto en el presente inciso, el fiscal podrá modificar la pena requerida para el evento de que el imputado admitiere su responsabilidad" 23 .

El texto transcrito, a diferencia del correspondiente al juicio abreviado, solo contiene una autorización para la modificación de la pena requerida, no así del requerimiento, entendiendo por tal su contenido fáctico y su calificación jurídica, por lo que determinar a qué obedece tal enmienda de la pretensión procesal ha generado aún mayor discordia entre los operadores de nuestro sistema penal, sobre todo si el legislador no sujetó expresamente tal modificación punitiva al reconocimiento de una mitigante específica ni a su operación conforme a las reglas generales, como sí lo hizo respecto del juicio abreviado. Mas, tal omisión legislativa no debe hacer creer que el codificador pretendió dejar completamente librada a la discreción del Fiscal la pena máxima que en definitiva aplicará el órgano jurisdiscen-

\footnotetext{
20 Así habría ocurrido en Italia, según explica MARAFioti (2008) p. 91.

21 En el mismo sentido Del Río (2008) p. 166.

22 Ministerio Público con Paredes (2012).

23 Ese texto es producto de la Ley No 20.074, de 14 de noviembre de 2005.
} 
te, pues la historia de su discusión legislativa da prueba de la preocupación por el abuso en la rebaja de penas que pudiera efectuarse en el marco de la negociación ${ }^{24}$.

Así pues, la rebaja de pena que autoriza el artículo 395, suele hacerse operar por el MP incluyendo en su requerimiento, condicionado a la admisión de responsabilidad del imputado, la mitigante del artículo 11 No 9 del CP, en analogía bonam partem de lo prescrito para el procedimiento abreviado, cuestión que ha sido aceptada mayoritariamente, y correctamente pensamos, por nuestra jurisprudencia ${ }^{25}$. Desde luego cabe también hacer extensiva a este procedimiento la posibilidad de retirar material fáctico del requerimiento, en la forma ya explicada para el juicio abreviado, si es verdad que ella obedece a una adecuación, tanto en lo fáctico como en lo jurídico, a los mandatos del principio de objetividad, y por ende, de aplicación general a cualquier procedimiento especial.

Amén de las modificaciones de pena que respondan a los dos aspectos examinados, al igual que en el procedimiento abreviado, pareciera que la regulación pertinente no da cabida a mayores variaciones del requerimiento, cuestión que como estudiaremos a continuación, también ha sido sobrepasada por la realidad forense.

\section{VINCULATIO POENA}

Para que la morigeración de la sanción postulada por el Fiscal sea un real incentivo que provoque o induzca la renuncia del imputado al juicio oral, es que ambos procedimientos en análisis contemplan un tipo de vinculatio poena, que impide al tribunal sancionar en forma más gravosa que la postulada por el MP. De ahí la necesidad de un temprano control judicial sobre tal ofrecimiento, el que de omitirse, se erigirá como un límite punitivo que más tarde el tribunal no podrá franquear, no obstante que dicho marco responda a una incorrecta aplicación de la ley penal.

En particular, en el procedimiento simplificado de resolución inmediata, el tribunal no podrá imponer en la sentencia una pena superior a la solicitada por el Fiscal en el requerimiento (artículo 395, inciso $2^{\circ}$, del CPP) ${ }^{26}$, mientras que en el juicio abreviado, el juez no podrá aplicar una pena superior ni más desfavorable a la requerida por el Fiscal o el querellante, en su caso (artículo 412, inciso $1^{\circ}$, del CPP). Aun cuando el primer veto pareciera solo consistir en no superar la cuantía de la pena pretendida por el Fiscal, debe observarse igualmente, en analogía in bonam partem, el artículo 412 antes citado, que extiende esta proscripción a las penas más desfavorables, mayor cobertura que adquirirá importancia respecto a delitos con sanciones alternativas de diversa naturaleza.

En uno y otro procedimiento la pena que no podrá superar el sentenciador es aquella modificada por el Fiscal a raíz de la negociación con el imputado y su defensa para la renuncia al juicio oral y no la contenida originalmente en el requerimiento y acusación, en su caso,

\footnotetext{
${ }^{24}$ Segundo Informe de la Comisión del Senado. v.t. Mensaje No 440-350 de 22 de enero de 2004 que acompañó al Proyecto correspondiente a la Ley No 20.074.

25 v. Ministerio Público con Sivoli (2006); y Ministerio Público con Varas (2008).

26 v. Letelier con Rencoret (2010).
} 
pues de lo contrario la limitación al tribunal no tendría en general efecto alguno, ya que en dichas presentaciones comúnmente se persigue la pena máxima autorizada por la ley.

\section{INSUFICIENCIA DE LAS MODALIDADES DE RETRIBUCIÓN ANALIZADAS}

Cury $^{27}$, ya antes de la entrada en vigencia del CPP, anticipaba la necesidad de reformar la ley penal sustantiva, pues su sistema de determinación de pena dejaba al Fiscal sin opciones de negociación con el imputado. Llevaba la razón este profesor, pues tanto la retirada de elementos fácticos del inicial requerimiento o acusación y/o la modificación de la calificación jurídica, en adecuación a las reales y razonables posibilidades de acreditación y subsunción por parte del MP, así como la adición de la minorante del artículo 11 No 9 del CP, han resultado insuficientes para incentivar o instar al imputado a renunciar al juicio oral.

En el primer caso, ya sea porque las defensas han aprendido a reconocer que tales rebajas y modificaciones no constituyen ninguna concesión de parte del MP para su defendido, sino solo un ajuste a lo que razonablemente podrían demostrar en un juicio oral, razón por la que nada exponen sometiéndose a este.

Y en cuanto a la incorporación al requerimiento o a la acusación de la atenuante del artículo 11 No 9 del CP, esta resulta muchas veces una parca recompensa para el requerido o acusado que renuncia al juicio oral -si se coteja con la rebaja de un tercio de la pena que permiten los procedimientos italianos del patteggiamento y abbreviato, y el juicio rápido español, por ejemplo-, pues dicha modificatoria necesitará para operar una rebaja relevante de la pena -siquiera de un grado-, el concurso de al menos otra mitigante (artículos 67, inciso $4^{\circ}$, y 68 , inciso $3^{\circ}$, del CP), o su consideración como muy calificada (artículo 68 bis del CP), y siempre bajo el supuesto que no se presente también alguna agravante que podría anular su efecto. Con todo, ante el alto grado de reincidencia en el sistema criminal nacional ${ }^{28}$, incompatible con la mitigante del artículo 11 No 6 del CP de irreprochable conducta anterior, el reconocimiento de la minorante del artículo 11 No 9 del CP por la renuncia al juicio oral, ya sea simplificado u ordinario, solo producirá un acotado efecto que no resultará -ni lo ha sido en la realidad aplicativa- atractivo para el imputado y su defensa, atendida la criticada tradición de nuestros tribunales de fijar la cuantía de las penas en el mínimo del marco legal, desentendiéndose de la obligación de adecuarlas y fundamentarlas conforme a los parámetros del artículo 69 del CP”29.

Son estas cortapisas para retribuir adecuadamente la renuncia al juicio oral que efectúa el requerido o acusado, las que han llevado a que el MP sistemáticamente modifique sus requerimientos y acusaciones, así como las penas pretendidas, mucho más allá de la mera incorporación de la atenuante del artículo 11 No 9 del CP al juego operativo de las normas de determinación de pena, incurriendo en diversas prácticas de cuestionable legalidad, incluso en contravención a los dictámenes de la autoridad máxima del propio MP,

\footnotetext{
27 Cury (2000) p. 298.

28 v. Morales et al. (2012).

29 Sobre esta deuda de la jurisdicción, v. Matus y Van Weezel (2003) p. 374; Politoff, Matus y Ramírez (2004) p. 537; Novoa (2005) T. II, p. 353; Cury (2005) p. 699; y, Medina (2009) p. 209.
} 
la que uniforme y reiteradamente ha desestimado la alteración de cargos en la acusación, instruyendo a los Fiscales -sin éxito por cierto- que "se atengan estrictamente al mérito de la investigación y no modifiquen su acusación por delitos de menor penalidad, con el objeto de llegar a un procedimiento de esta naturaleza, pues ello es contrario al principio de legalidad"30.

\section{PRÁCTICAS MÁS COMUNES UTILIZADAS PARA RETRIBUIR LA RENUNCIA DEL JUICIO ORAL ${ }^{31}$}

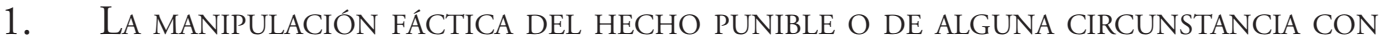 EL FIN DE DAR LUGAR A UNA CALIFICACIÓN MENOS GRAVE \\ Esta primera práctica consiste en recortar los hechos que razonablemente podrían} acreditarse con los antecedentes investigativos reunidos por la Fiscalía, con el fin de hacerlos encajar en la calificación más beneficiosa para la negociación, con independencia de su correspondencia con la realidad de los antecedentes de cargo. Mediante esta conducta no solo se pretende disponer de la pura construcción del relato fáctico de manera consensuada, sino que tras aquello lo que se busca, es disponer de la norma sustantiva ${ }^{32}$. Tal sería el caso de la retirada del actuar sorpresivo en la sustracción de una especie portada por el ofendido, de manera de transitar del delito de robo por sorpresa al hurto, o la omisión del porte de arma de fuego en el delito de robo en lugar habitado, que agravaría sustancialmente la pena de este.

Así, por ejemplo, en causa RUC No 1100231952-9, del 2 Juzgado de Garantía de Santiago, sentencia de 17 de abril de 2012, el MP presentó requerimiento de procedimiento simplificado por el siguiente hecho: “(...) cuando personal de carabineros lo sorprendió en estado de ebriedad conduciendo el camión (...), el cual quedó evidenciado no solo por su incoherencia al hablar y rostro congestionado, sino además por el examen de alcoholemia que se le practicó, el cual arrojó que el imputado conducía con 2.13 gramos por mil de alcohol en la sangre”. Este hecho lo calificó el MP como delito de conducción de vehículo en estado de ebriedad, solicitando la pena de 300 días de presidio menor y multa de 2 UTM, además de la suspensión de licencia de conducir por el término de 1 año. En la audiencia de procedimiento simplificado el MP reformula los hechos de la siguiente manera: “(...) se encontraba en el interior del camión (...), durmiendo, con el motor en marcha y con las puertas abiertas, el que estaba estacionado en ese lugar cuando fue fiscalizado, por lo que se aprestaba a conducir en estado de ebriedad", calificando ahora estos sucesos como constitutivos del "delito de aprestarse a conducir vehículo motorizado en estado de ebriedad" (sic.), "en grado de tentativa" (sic.), solicitando para el evento de admisión de respon-

\footnotetext{
30 Oficio de la Fiscalía Nacional No 286/2010, de 31 de mayo de 2010.

31 En esta parte seguiremos fundamentalmente la exposición de Del Río (2009b) pp. 77-109, al tratar lo que él ha llamado como "prácticas inadecuadas sobre el procedimiento abreviado en la jurisprudencia". Algunas de las prácticas que revisaremos han sido respaldadas, con diferencias, por buena parte de nuestra doctrina, v. Oberg (2000) p. 162; Mera (2004) pp. 252-253; Cerda y Hermosilla (2006) p. 716; Sáez (2007) p. 18; Salas (2009) p. 226; Maturana y Montero (2010) T. II, p. 1063; y, Correa y Reyes (2011) p. 95. v.t. Letelier con Rencoret (2010).

32 Del Río (2009b) pp. 81-82.
} 
sabilidad la pena de 21 días de prisión, multa de 1/5 de UTM y suspensión de licencia de conducir por el plazo de 7 meses. Es decir, se modifican los hechos, pasando de la conducta de conducir el vehículo a aprestarse a conducirlo, con la consiguiente rebaja de penalidad dispuesta en el artículo 182, inciso final, de la Ley No $18.290^{33}$.

En este y otros casos ya vistos y que se verán luego, la pretensión punitiva suele quedar reducida a menos de un diez por ciento de la primitiva, movimiento pendular que, con aguda razón es cuestionado por Del Río ${ }^{34}$, tanto porque la variedad y heterogeneidad de la práctica demuestra que no se obedece a ningún criterio racional y preestablecido, sino a la pura utilidad del caso a caso guidada por el fin de provocar el consenso, y por otra parte, en atención a que las aceptaciones obtenidas con ofrecimientos de rebajas punitivas como las comentadas no pueden considerarse voluntarias.

\section{La CALIFICACIÓN JURÍdica PRESCINDE DEL HeCHO DE LA ACUSACIÓN, Y LA}

INCORRECTA MODIFICACIÓN DE LA CALIFICACIÓN JURÍDICA DE LA ACUSACIÓN A TRAVÉS DE LA DEGRADACIÓN DE ESTA

En el primer supuesto de estudio, el acusador público intencionadamente realiza una calificación jurídica que se basa en hechos sustancialmente distintos -e inexistentes- a los planteados en la acusación, la cual se mantiene en este aspecto inalterada. En otras palabras, se califica jurídicamente con prescindencia del hecho ${ }^{35}$.

En la causa RUC No 0400129328-7, del Juzgado de Garantía de San Pedro de la Paz, sentencia de 4 de mayo de 2004, se presenta requerimiento de procedimiento simplificado por el siguiente hecho: “(...) el imputado junto a otra persona, sustrajo desde la parte posterior de la Empresa (...), 5 planchas de melamina de propiedad de esta Empresa, las cuales cargó en un carretón de su propiedad, huyendo del lugar y siendo posteriormente detenido por personal de Carabineros de la Subcomisaría de San Pedro de la Paz, a unos seiscientos metros del lugar, mientras transportaba en este carretón las referidas planchas. Las especies fueron avaluadas en la suma de \$90.000 por la ofendida”. Estos hechos fueron calificados por el MP como delito de hurto, respecto de los cuales se pide la imposición de una pena de 61 días de presidio y multa de 5 UTM. En audiencia posterior, sin modificar los hechos, el MP los califica ahora como delito de receptación, no obstante que sigue imputándole al requerido haber sido él mismo quien sustrajo el objeto. Esta alteración no fue prevenida ni impedida por el Tribunal, que condena al hechor en base a la calificación propuesta únicamente a una multa de 5 UTM -obviando la pena privativa de libertad asignada en la ley-, y suspendiendo además su pago conforme al artículo 398 del CPP -en

\footnotetext{
${ }_{33}$ Como consta en la Ministerio Público con Vallade (2009), en la audiencia de procedimiento simplificado el MP reduce el número y valor de los objetos sustraídos indicados en el requerimiento, pasando del delito a la falta de hurto. Una situación similar se advierte en Ministerio Público con Varas (2009): del Juzgado de Garantía de Valdivia. Mientras, en causa Ministerio Público con Valenzuela (2009), se formaliza por el delito de robo en lugar habitado, y posteriormente se reformaliza, modificando los hechos y calificándolos ahora de delito de receptación, figura por la que en definitiva sanciona el Juzgado de Garantía con fecha 21 de enero de 2013 en procedimiento simplificado.

34 Del Río (2009b) pp. 102, 134-135. Lo último, apoyándose en Schünemann y en la jurisprudencia alemana.

35 Del Río (2009b) p. 85.
} 
patente contradicción con este último precepto que permite tal resolución solo respecto de las faltas-.

Situaciones como la recién extractada son aún más graves, desde que, en opinión de Del Río ${ }^{36}$, dan cuenta además de la infracción al deber de correlación, pues detrás de una modificación de la calificación como la indicada, lo que hay en realidad es un cambio sustancial del hecho enjuiciado.

En la causa RUC No 1000736623-5, del Juzgado de Garantía de Antofagasta, se presentó acusación por los siguientes hechos: “(...) en circunstancias que la víctima (...) efectuaba sus labores como repartidor de la empresa Coca Cola conduciendo el camión (...) detuvo la marcha para entregar bebidas, momentos en los cuales el imputado (...) procedió a subirse a las pisaderas de la puerta del costado izquierdo del camión portando en una de sus manos un cuchillo de regular tamaño, con el cual lo intimidó, colocándoselo a la altura del cuello, instantes en que le exigía la entrega de dinero, manifestándole con groserías que le entregara la plata si no lo mataba, situación que fue observada por uno de los peonetas, el cual, salió en defensa de la víctima, lo que provocó que el imputado huyera del lugar, ingresando sin la autorización de su propietario (...) al domicilio ubicado en calle Plumerillo No 6390, siendo detenido por los funcionarios policiales en el interior del inmueble”. Estos hechos fueron bien calificados en la acusación del MP como delito de robo con intimidación, solicitando la imposición de una pena de 10 años de presidio. Sin embargo, en la audiencia de preparación de juicio oral, se modifica la calificación de los hechos ya reproducidos a los delitos de amenazas no condicionales y violación de morada, condenando el Juzgado de Garantía mediante un procedimiento simplificado por ambos delitos con fecha 28 de enero de 2011, a dos penas de 61 días de presidio ${ }^{37}$.

En la segunda situación a examinar enunciada al comienzo de este apartado, también se produce una modificación de la calificación jurídica de los hechos de la acusación inicial -los que se mantienen intactos-, pero específicamente mediante una degradación delictiva, esto es, desplazando la calificación hacia un tipo menos grave, pero casi siempre homogéneo ${ }^{38}$.

En la causa RUC No 1200195393-K, del Juzgado de Garantía de Colina, sentencia de 31 de enero de 2013, el MP acusó por los siguientes hechos: “(...) el imputado (...) abordó en la intersección de los pasajes Araucaria con Los Nogales de la Comuna de Colina a la víctima (...), a quien intimidó con un cuchillo exigiéndole la entrega del teléfono móvil que portaba consigo, de esta forma, la víctima entregó por la intimidación del imputado el teléfono que traía, dándose a la fuga el imputado con la especie de la víctima, ingresando este a un domicilio del sector, lugar de donde sacó un elemento contundente, esto es, un palo con el cual además golpeó en un brazo a la víctima quien lo había seguido hasta dicho lugar, exigiéndole la especie. Producto de la agresión la víctima resultó con 'contusión de brazo izquierdo' de carácter leve”. Estos hechos fueron calificados correctamente por el

36 Del Río (2009a) pp. 262-263.

37 Igualmente patente es lo discrecional del cambio de calificación en la Ministerio Público con Muñoz (2007). Cabe destacar que esta modificación de calificación suele también realizarse, no en relación a la acusación o requerimiento original, sino respecto de los hechos que fueron materia de formalización, así se observa en $M i$ nisterio Público con Campos (2011).

38 Del Río (2009b) p. 89. 
MP como robo con violencia e intimidación, sin embargo, en la audiencia de preparación del juicio oral, sin modificar los hechos, ahora se califican erróneamente como robo por sorpresa, a fin de someter su juzgamiento bajo las normas del procedimiento abreviado. El Juzgado de Garantía acepta el procedimiento abreviado, no obstante que en el fallo califica los hechos como robo con violencia ${ }^{39}$.

\section{El abandono de hechos agravantes (existentes) o la inclusión de ATENUANTES (INEXISTENTES) ${ }^{40}$}

Usualmente el acusador público retira discrecionalmente de su acusación o requerimiento, a fin de pavimentar la negociación con el imputado, agravantes avaladas por la investigación y que se invocaban en la acusación, regularmente la reincidencia del imputado (artículo 12 No 15 ó 16 del CP) o la pluralidad de malhechores (artículo 456 bis No 3 del CP).

En causa RUC No 1300108869-0, del $2^{\circ}$ Juzgado de Garantía de Santiago, sentencia de 30 de enero de 2013, el MP presenta requerimiento por el delito de hurto, considerando la agravante del artículo 12 No 16 del CP (reincidencia específica), la que posteriormente retira para el caso de admisión de responsabilidad del imputado, lo cual sucede. El tribunal en su fallo no se pronuncia sobre la concurrencia de esta agravante no obstante que deniega beneficios de la Ley No 18.216 fundándose en las condenas anteriormente impuestas al requerido por diversos delitos que legalmente permiten configurar la agravante omitida $^{41}$.

Por otra parte, igualmente el MP, con los fines ya tan comentados, postula atenuantes sin respaldo o a todas luces no configuradas legalmente, como la reparación celosa del mal causado (artículo 11 No 7 del CP) mediante consignación de sumas ínfimas y desproporcionadas al daño ocasionado.

De lo último, podemos citar la sentencia del $12^{\circ}$ Juzgado de Garantía de Santiago, RUC No 1200604349-4, de 8 de enero de 2013, donde el MP plantea, en relación al deli-

39 Se constata el tránsito desde el delito de amenazas a la falta del artículo 494 No 4 del CP, en Ministerio Público con Zapata (2012), Ministerio Público con Contreras (2012) y Blanco con Arguedas (2012); Hernández con Alarcón (2012); Cifuentes con Yáñez (2012); Ministerio Público con Guzmán (2012); y, Ministerio Público con González (2010). Desde el delito de daños calificado a simple, v. Torres con Ossandón (2011), y del delito a la falta de daños, v. Cifuentes con Yáñez (2012).

40 Se ha seguido también en esta parte a Del Río (2009b) pp. 98 y ss.

${ }^{41}$ También se aparta la agravante del artículo 12 No 16 del CP de la acusación o requerimiento, según consta en la sentencia Ministerio Público con Varas (2008); sentencias del Juzgado de Garantía de Coquimbo, RUC No 0600002316-5, de 23.01.2007, Ministerio Público con Madariaga (2009), Villanueva con Sánchez (2010) Ministerio Público con Ardiles (2012); Ministerio Público con González (2012); Ministerio Público con Vergara (2006); Ministerio Público con Galarce (2012); sentencia del Juzgado de Garantía de San Antonio, RUC No 1100808115-K, de 14.12.2011; Ministerio Público con Espina (2013), y RUC No 1200275891-K, de 23.01.2013. En lo concerniente a la agravante del artículo 12 No 15 del CP, v. Vásquez con Acuña (2012); sentencia del Juzgado de Garantía de San Antonio, RUC No 1000336390-8, de 30.09.2011; y Ministerio Público con Núñez (2010). En cuanto a la agravante del artículo 456 bis No 3 del CP, v. Riquelme con Ramírez (2012); Ministerio Público con Medina (2008) y Ministerio Público con Varas (2008); Ministerio Público con Águila (2010); Ministerio Público con Mejías (2010) y Ministerio Público con Roa (2013); Ministerio Público con Alonso (2012); Ministerio Público con Figueroa (2009), Ministerio Público con Madariaga (2009), RUC No 1000885537-K, de 11.04.2011, y, Ministerio Público con Pardo (2012); Ministerio Público con Damanes (2008); y, Ministerio Público con Ruiz (2009). 
to de robo en lugar habitado, la concurrencia de la mitigante del artículo 11 No 7 del CP con la consignación de una suma de $\$ 7.500$, pese a que el artículo 456 bis, inciso final, del $\mathrm{CP}$ prescribe que respecto de ese delito "el juez deberá considerar, especificada, la justificación del celo con que el delincuente ha obrado" ${ }^{2}$.

\section{Sin alterar los hechos o su encuadre jurídico el Ministerio Público ANTICIPA EN SU REQUERIMIENTO O ACUSACIÓN UNA REBAJA DE PENA QUE EL LEGISLADOR DEJA A DISCRECIÓN DEL JUZGADOR}

Para cumplir el mandato legal del artículo 391 letra e) del CPP, el cual prescribe que el requerimiento debe contener: "la pena solicitada por el requirente", el Fiscal debe echar a andar todas las normas de determinación de la pena, algunas de las que, más allá de su carácter legal o judicial, implican un ejercicio facultativo -mas no arbitrario ${ }^{43}$ - para el tribunal. Por ejemplo, aquellas rebajas de grado que obedezcan a la concurrencia de una pluralidad de mitigantes de responsabilidad penal (artículos 65, 66, 67 y 68 del CP), o a la consideración como muy calificada de alguna atenuante (artículo 68 bis del CP), así como la determinación de la cuantía específica de la pena dentro del grado (artículo 69 del CP).

En este contexto, es usual que el MP incluya ya en el petitorio de la acusación de procedimiento abreviado o del requerimiento de procedimiento simplificado (ya sea como pena originalmente solicitada o resultado de la negociación con el imputado y su defensa) el influjo del artículo 68 bis del CP, esto es, considerar alguna atenuante como muy calificada, lo que conlleva el efecto extraordinario de rebajar en un grado la pena, no obstante que dicha calificación está entregada por la ley a la discreción del juzgador ${ }^{44} \mathrm{y}$, por tanto, no puede anticiparse en la pretensión punitiva del Fiscal ${ }^{45}$.

No obstante los reparos comentados, podemos citar diversos casos en que el MP contempla ya en el quantum de la pena solicitada en su acusación o requerimiento, los

\footnotetext{
${ }^{42}$ Igual situación se aprecia en Ministerio Público con Ardiles (2012); y Ministerio Público con Ferrada (2013). En la causa Abalos con Rencoret (2010), se presentó requerimiento por el MP por cuasidelito de homicidio, en el que hace valer tres atenuantes (artículo 11 No 6,7 y 9 del CP) para solicitar una pena de 30 días de prisión. Una vez admitida responsabilidad por el imputado, en su fallo la sentenciadora estimó que no concurrían dos de las mitigantes alegadas por el MP -artículo 11 No 6 y 7 del CP-, procediendo legalmente la imposición de una pena entre 61 y 540 días de presidio, sin embargo, sanciona en definitiva con fecha 4 de noviembre de 2010, a la pena inferior requerida por el MP en virtud de lo dispuesto en el artículo 395, inciso $2^{\circ}$, del CPP, y argumentando que: "toda vez que ya admitida la responsabilidad penal por el encausado, se ha fijado el límite máximo de pena a imponer, encontrándose el tribunal vedado de aplicar una pena superior a ella, siendo ya intrascendente a los efectos su pronunciamiento respecto de aquellas circunstancias modificatorias de responsabilidad penal"

43 GARRIDO (2001) T. I, p. 307, explica que "el juez cuenta con una relativa discrecionalidad para la determinación de la pena dentro del marco legal, pero esa discrecionalidad no es absoluta, debe respetar los principios jurídicos que la orientan y los fines que esta persigue (prevención general y especial, merecimiento y necesidad de la sanción)". Otras apreciaciones, en Medina (2009) p. 203; y, NovOA (2005) T. II, pp. 352-353. En el ámbito comparado, v. Quintero, Morales y Prats (1996) p. 539; Maurach, Gössel y Zipf (1994) p. 794; Jescheck y WeIGEND (2002) pp. 938-939.

44 v. entre otros, Bullemore y Mackinnon (2005) T. I, p. 153. También nuestra jurisprudencia, en sentencia de la Corte Suprema, Barahona Larenas (2006); Corte de Apelaciones Herrera con Romero (2006); y Valencia con Abarca (2006).

${ }^{45}$ Horvitz (2005) T. II, pp. 521-522.
} 
efectos del artículo 68 bis del CP, así por ejemplo, en causa del Juzgado de Garantía de Curacaví, RUC No 1101256974-4, sentencia de 27 de noviembre de 2012, el MP solicita respecto del delito consumado de robo en bien nacional de uso público, una pena de 61 días de presidio que ya considera anticipadamente la calificación del artículo 68 bis del CP a la mitigante del artículo 11 No 9 del CP, concediéndose esta por la sola admisión de responsabilidad en el procedimiento simplificado de resolución inmediata ${ }^{46}$.

Lo arriba razonado creemos puede calzar con otras dos situaciones específicas donde la rebaja de pena debiera quedar entregada facultativamente a la discreción del tribunal.

En primer término, la fijación de la cuantía de la multa bajo el mínimo legal (artículo 70 , inciso $1^{\circ}$ in fine, del $\mathrm{CP}$ ), pues se ha reconocido el carácter facultativo de su determinación judicial, aun cuando debe ser razonada y fundada en la sentencia ${ }^{47}$. Entre muchos casos en que se plantea tempranamente por el MP una disminución de la multa que obsta su fijación por el tribunal, podemos citar la sentencia del Juzgado de Garantía de Coquimbo, RUC No 1001051563-2, de 6 de diciembre de 2011, donde consta que por el delito de receptación objeto del requerimiento se pide por el MP una multa de 1 UTM, en circunstancias que el mínimo legal es de $5 \mathrm{UTM}^{48}$.

$\mathrm{Y}$ en segundo lugar, la rebaja en dos o tres grados de una pena divisible de uno o más grados (artículos 67, inciso $4^{\circ}$, y 68, inciso $3^{\circ}$, del CP). En este punto hoy la doctrina predominantemente estima como facultativas para el juez tanto la rebaja de la pena como el monto de ella ${ }^{49}$, no obstante lo cual, encontramos ejemplos de tal anticipación, como en la sentencia del Juzgado de Garantía de Coquimbo, RUC No 1100172703-8, de 4 de enero de 2012, en la que se deja constancia que respecto del delito de robo en lugar habitado, y concurriendo dos mitigantes (artículo 11 No 7 y 9 del CP), el MP solicita una pena de 541 días de presidio, es decir, dos grados bajo el mínimo, sanción que en definitiva impone el Juzgado de Garantía escudándose en la limitación que le significa la norma del artículo 412 del CPP ${ }^{50}$.

46 También v. Ministerio Público con González (2010); Ministerio Público con Vergara (2006); sentencia del Juzgado de Garantía de San Antonio, RUC No 1100808115-K, de 14.12.2011; Ministerio Público con Espina (2013) y RUC No 1200275891-K, de 23.01.2013; Ministerio Público con Caris (2013), Salinas con Carrasco (2013) y Sánchez con Moreno (2013); sentencia del Juzgado de Garantía de Linares, RUC No 1200229 Ministerio Público con Ferrada (2013); Carabineros de Chile con Araya (2013); y Ministerio Público con Opazo (2009).

47 Van Weezel (1997) p. 470; y, Matus y Van Weezel (2003) p. 377.

48 v.t. Ministerio Público con Zapata (2012), donde consta que el MP presenta requerimiento por hechos que califica como delito del artículo 288 bis del CP, pidiendo se imponga la multa de 1/5 de UTM, en circunstancias que el mínimo legal es de 1 UTM; Ministerio Público con Águila (2010), revela que respecto del delito de hurto del artículo 446 No 2 del CP, el MP pide se imponga a los imputados sendas multas de 2 y 3 UTM, en circunstancias que el mínimo legal es de 6 UTM; Cerda con Cáceres (2013), se demuestra que respecto del delito de hurto (artículo 446 No 3 del CP), el MP pide que se imponga al imputado la multa de $1 / 3$ de UTM, en circunstancias que el mínimo legal es de 5 UTM.

49 v. VAN Weezel (1997) p. 470; Garrido (2001) T. I, p. 322; Etcheberry (2001) T. II, pp. 185-187; Matus y Van Weezel (2003) pp. 360 y ss.; Politoff, Matus y Ramírez (2004) p. 533; Novoa (2005) T. II, p. 362; Cury (2005) 769; y Medina (2009) 209. Un compendio de la discusión doctrinal nacional en RudniCK (2007) pp. 453 y ss.

50 Igualmente en Tagle con Fuster (2010), consta que, concurriendo dos atenuantes, el MP requiere penas de 77 días de presidio por delitos de uso malicioso de instrumento privado mercantil falso, el que tiene asignada una pena de presidio menor en su grado máximo. Una anómala e inversa modalidad de anticipación con los 
No creemos sin embargo, que en la última situación comentada (artículos 67, inciso $4^{\circ}$, y 68 , inciso $3^{\circ}$, del CP), si concurren los presupuestos objetivos -dos o más atenuantes y ninguna agravante-, pueda verse como un arrebato de las facultades jurisdiccionales del tribunal por parte del MP si la pretensión punitiva de este en su acusación o requerimiento ya comprende la rebaja solo de un grado de la pena, pues no hay acuerdo en nuestra cátedra si en este supuesto la reducción de pena en un grado es facultativa u obligatoria para el órgano jurisdiccional ${ }^{51}$. Asimismo, aun cuando nuestra doctrina está conteste en que es discrecional y privativo del tribunal la determinación de la pena concreta dentro del grado ${ }^{52}$ conforme prescribe el artículo 69 del CP, tampoco podría objetarse que el MP en su acusación o requerimiento pida una pena concreta (por ejemplo, 61 días de presidio) y no el grado resultante de las normas de determinación de pena (siguiendo el ejemplo anterior, presidio menor en su grado mínimo). Si bien con ello se afecta la exclusividad de la actividad jurisdiccional si el Fiscal, en el procedimiento simplificado de resolución inmediata o en el juicio abreviado, pide el mínimo de la pena dentro del grado aplicable al caso, al impedirle actualizar los criterios contemplados en el artículo 69 citado y eventualmente fijar en una cuantía superior la pena dentro del grado correspondiente (en virtud de lo prescrito en los artículos 395 , inciso $2^{\circ}$, y 412 , inciso $1^{\circ}$, del CPP) $)^{53}$, no puede preterirse que la solicitud de una pena concreta viene demandada por las normas procesales y orgánicas que asocian el procedimiento como la competencia del tribunal juzgador a la pena específica anunciada por el MP (artículos 388, inciso $2^{\circ}$, y 406, inciso $1^{\circ}$, del CPP, 14 c) y e) y 18 a) del Código Orgánico de Tribunales).

\section{CONTROL JUDICIAL SOBRE LA DISCRECIONAL MODIFICACIÓN A LA ACUSACIÓN O REQUERIMIENTO DEL MINISTERIO PÚBLICO}

La concatenación de los apartados desarrollados anteriormente en este capítulo pone en evidencia la necesidad de contar con un definido y robusto control judicial que examine la legalidad de las modificaciones al requerimiento o acusación efectuado por el MP en el marco de las negociaciones llevadas a cabo en el procedimiento simplificado de resolución

efectos ya relatados, podría darse mediante un pacto entre MP e imputado que limite la exasperación de la pena resultante de la aplicación de las normas de acumulación jurídica del artículo 351 del CPP, supuesto en el que el MP interesa la irrogación de una pena elevada solo en un grado, y no en dos como autoriza la norma precitada, limitando luego al tribunal si este considera que el aumento debió haber sido mayor. Lo anterior se intentó en Ministerio Público con Werner (2006), se rechaza el procedimiento abreviado solicitado por las partes, por estimar que la aplicación del artículo 351 del CPP conducía a elevar la pena en dos grados, y no en uno como planteaba el MP en su acusación, superándose con ello en el caso en comento el límite máximo que tolera el procedimiento abreviado

51 Sosteniendo, con la minoría de la doctrina, la obligatoriedad de la rebaja de pena por concurrencia de circunstancias atenuantes, MaÑALICH (2010) pp. 54 y ss.

52 Etcheberry (2001) T. II, p. 184; Van Weezel (1997) p. 463; y, VAn Weezel (2001) p. 406.

53 Más aún si, como sentencia Etcheberry (2001) T. II, p. 191, el artículo 69 del CP es "un precepto imperativo para el sentenciador, de modo que este está obligado a consignar en su fallo la forma en que ha dado cumplimiento a lo dispuesto en este artículo". Sobre la privación del poder de connotación o comprensión equitativa, v. Ferrajoli (2001) p. 39. 
inmediata y en el juicio abreviado, antes de dictarse sentencia ${ }^{54}$. De no existir, o de no operar adecuadamente dicho control preliminar, el tribunal al fallar se vería impedido de imponer la pena correspondiente a la calificación jurídica y sus circunstancias modificativas que estime ajustada a los hechos acreditados, pues la prohibición para superar la pena perseguida por el Fiscal prescrita en los artículos 395 y 412 del CPP lo obstaría ${ }^{55}$, violentándose de ese modo el principio y garantía de exclusividad de la jurisdicción ${ }^{56}$.

En este asunto, como en tanto otros, el ordenamiento nacional es incompleto y lagunar, pues no entrega taxativamente al órgano jurisdiccional herramientas eficaces para desarrollar tal control, y de ahí la incertidumbre y diversidad en el tratamiento dado a esta materia por nuestros tribunales, nocivo estado que ha contribuido a la expansión de las prácticas discrecionales arriba comentadas ${ }^{57}$.

\section{Control Judicial de Admisibilidad EN EL JUicio ABREVIAdo y EN EL} PROCEDIMIENTO SIMPLIFICADO DE RESOLUCIÓN INMEDIATA

\section{A. Juicio abreviado}

El procedimiento abreviado contempla un examen de admisibilidad de la procedencia del mismo llevado a cabo por el Juzgado de Garantía, resultado del cual este aceptará o desestimará la solicitud de juicio abreviado. Si esta es desestimada, en caso de haberse ya formulado acusación escrita, se procederá a preparar el juicio oral, y en caso contrario se continuará el procedimiento según el estado en que se encontrase al momento de formularse la acusación, ya sea pendiente el cierre de la investigación o cerrada esta etapa pero faltante la presentación de la acusación, o presentada esta pendiente la audiencia de preparación del juicio oral ${ }^{58}$.

Para aceptar la solicitud de procedimiento abreviado, el tribunal debe verificar las siguientes condiciones: a) que los antecedentes de la investigación fueren suficientes para proceder de conformidad a las normas de este procedimiento; b) la pena solicitada por el Fiscal no sea superior a 5 años de presidio o reclusión menores en su grado máximo, o bien

54 Control que, siguiendo a Alcalá-Zamora (1962) p. 198, se trataría de una suerte de casación al revés: no de una o más partes contra la sentencia del tribunal, sino del tribunal contra la declaración del acusado que vulnera la ley procesal (en cuanto no se atiene a los límites fijados estatutariamente) y la ley penal (en cuanto desconoce la correlación legal delito-pena).

55 Erróneamente se sostuvo lo contrario Ministerio Público con Allende (2006), que en apelación de sentencia de procedimiento abreviado, elevó la pena a 5 años y un día de presidio, en vez de declarar improcedente este procedimiento conforme a lo previsto en el inciso $2^{\circ}$ del artículo 414 del CPP.

56 Sobre la infracción de la garantía procesal de la estricta jurisdiccionalidad mediante estas prácticas, v. DEL Río (2009b) pp. 126-129. En dirección opuesta v. Tavolari (2005) p. 236, y Ministerio Público con Vicencio (2004).

57 Del Río (2010) p. 362, caracteriza nuestro modelo de consenso en el proceso penal como un sistema práctico que se desarrolla al margen de las previsiones normativas procesal y penales, y que por lo tanto ha dado lugar a un sistema altamente desregulado e irracional.

58 En este caso, se tendrán por no formuladas las acusaciones verbales realizadas por el Fiscal y el querellante, lo mismo que las modificaciones que, en su caso, estos hubieren realizado a sus respectivos libelos (artículo 407, inciso final, del CPP). 
cualesquiera otras penas de distinta naturaleza; c) el acuerdo hubiere sido prestado por el acusado con conocimiento de sus derechos, libre y voluntariamente; y d) de haberse opuesto el querellante al procedimiento abreviado, no considerare esta oposición fundada.

De los extremos enunciados nos interesan fundamentalmente para nuestro estudio los dos primeros, sin perjuicio que luego nos explayaremos sobre el último.

Respecto del examen de suficiencia de los antecedentes investigativos reunidos por el MP, despejemos que para llevarse a efecto, necesariamente demandará su exposición en forma previa al juicio propiamente tal, la que usualmente se realiza ya sea motu proprio por el MP, o a indicación del Juzgado de Garantía, para cumplir con otro de los presupuestos de admisibilidad de este procedimiento, esto es, que el acusado acepte los antecedentes de la investigación que fundan la acusación -lo que requiere por cierto su conocimiento-, de lo cual la mejor forma de cerciorarse fehacientemente por la autoridad judicial, es exigir que dicha presentación se realice en la propia audiencia en forma oral ${ }^{59}$. Lo anterior vuelve innecesario que, ya declarado procedente el juicio abreviado, el Fiscal vuelva a exponer los antecedentes de la acusación (como prescribe el artículo 411 del CPP), pasándose derechamente al debate de las partes sobre su mérito.

En un segundo orden, este examen de suficiencia para proceder conforme a las normas del procedimiento abreviado, tiene un objeto diverso al que nos interesa tratar ahora -esto es, el control y remedio judicial ante un ejercicio incompleto y fragmentado de la pretensión procesal en atención a que los hechos que razonablemente se podrían acreditar con los antecedentes investigativos acopiados por el Fiscal revisten mayor gravedad a los que son objeto de la acusación-, pues el examen sobre la suficiencia de antecedentes establecido por el legislador en el artículo 410 del CPP precisamente busca evitar lo contrario, es decir, que el imputado renuncie al enjuiciamiento en el procedimiento ordinario respecto de hechos que no están suficientemente acreditados con los registros de la investigación.

En efecto, tal suficiencia de antecedentes exigida por el legislador más bien fue muestra de su temor a que, ante la desigualdad de condiciones en la negociación entre el Fiscal y el imputado ${ }^{60}$, este renuncie al juicio oral no obstante la ausencia de antecedentes inculpatorios, en forma similar al plea bargaining estadounidense, para lo cual instaura un control sobre la base de las diligencias instructoras para prejuzgar si en ellas existe o no un suficiente acopio de material probatorio de cargo.

El Proyecto de CPP no contemplaba, dentro de los aspectos que el Juzgado de Garantía debía tener en cuenta para resolver si acogía o no a tramitación el procedimiento abreviado, un examen acerca de la suficiencia de los antecedentes de la investigación fiscal. El artículo 482 -actual artículo 410 inciso 1º- rezaba así: "Resolución. El juez dispondrá la tramitación conforme al procedimiento abreviado, cuando considerare que el acuerdo ha sido prestado por el acusado con conocimiento de sus derechos, libre y voluntariamente". Este extremo fue agregado en el Senado, junto con la prohibición de que la sentencia

\footnotetext{
59 En igual sentido SÁEZ (2007) p. 20.

60 Sobre esta asimétrica posición entre las partes que negocian en el proceso penal, y cómo esta se opone a una visión de la administración de justicia basada en la racionalidad del mercado que abraza la ideología de laissezfaire, v. DAMASKa (2010) pp. 91-92.
} 
condenatoria se emita exclusivamente sobre la base de la aceptación de los hechos por parte del imputado, prohibición que el Proyecto de CPP tampoco contemplaba. En el Segundo Informe de la Comisión del Senado se dejó constancia que "en primer lugar el requisito de aceptación de los hechos, al respecto, se indicó que hay dos maneras de abordar este tema. En el sistema norteamericano en que se le pregunta al imputado si se declara culpable o inocente y el otro el sistema europeo que se refiere solamente al procedimiento, en que el imputado se mantiene como inocente pero acepta renunciar a un juicio, sistema que no ha funcionado en la práctica porque la rebaja de pena es mínima y se rigidiza demasiado la investigación para poder utilizar los antecedentes en el juicio. Lo que pretende el proyecto es combinar ambos sistemas, exigiendo la aceptación de los hechos y antecedentes de la investigación, pero además que haya un examen de los antecedentes reunidos por la fiscalía para evitar que la condena se produzca por la sola confesión del imputado y se obliga al fiscal a limitar la pena solicitada”. Ya Pecchi ${ }^{61}$ precisamente había criticado a la sazón que no se hiciera referencia alguna en el Proyecto de CPP a que este procedimiento abreviado solo será aplicable siempre que previamente se encuentre suficientemente acreditado el hecho punible por otros medios que no sea el reconocimiento de participación que hace el imputado.

En consonancia con lo expuesto, ha devenido en un lugar común para nuestra doctrina iusprocesalista, exigir una suficiencia razonable de los antecedentes para respaldar los hechos de la acusación en este examen de admisibilidad -lo que no se demanda en el procedimiento ordinario-, es decir, que exista al menos un antecedente, aunque sea sucinto, para comprobar cada elemento de la acusación ${ }^{62}$. En esto, la doctrina nacional está a la par de la foránea, la cual destaca que aun cuando un sistema permita cualquier modalidad de justicia negociada, solo debe permitirse el acceso a esta cuando el órgano jurisdiccional haya determinado, en primer lugar, la existencia de indicios racionales que permitan ejercer la acción penal ${ }^{63}$.

Así las cosas, atribuir a este examen, que como vimos se dirige a confirmar la suficiencia de antecedentes que sustenten la acusación, otro aspecto diametralmente opuesto que permitiría corregir ahora la insuficiencia de la acusación ante los mismos antecedentes reunidos, permitiendo de algún modo -u obligando- al juez a verificar que no se haya desestimado en la acusación hechos que se encuentran debidamente justificados en los registros de la investigación, resultará igualmente dificultoso ${ }^{64}$.

Y, en cuanto al segundo extremo sujeto a control judicial, esto es, que la sanción solicitada por el Fiscal no sea superior a una pena privativa de libertad de cinco años de

\footnotetext{
61 PeCCHI (2000) p. 178.

62 Entre otros, Cerda y Hermosilla (2003) p. 46; Horvitz (2005) T. II, p. 527; Maturana y Montero (2010) T. II, p. 1074; y, Correa y Reyes (2011) p. 93. Algunos autores han ido más allá, intensificando en mayor o menor grado este control de admisibilidad, al respecto v. NúNÉEZ (2003) T. II, p. 445; FALCONE (2005) pp. 371 y ss.; SÁez (2007) p. 19; Del Río (2009b) p. 139 y n. 159; y Salas (2009) pp. 270-271. Sobre el exigente examen de admisibilidad requerido por la doctrina argentina para la procedencia del juicio abreviado, v. CAFFERATA (2000) pp. 168 y ss.

63 Díaz (1996) pp. 285-286.

${ }^{64}$ No obstante ello, podemos encontrar jurisprudencia que apunta en el sentido por nosotros desestimado, v. Ministerio Público con Marín (2004).
} 
presidio o reclusión menores en su grado máximo, o bien cualesquiera otras penas de distinta naturaleza, sin perjuicio de lo que luego expondremos, la acotada prescripción del legislador en principio aparenta limitar este control judicial a una mera constatación formal de la conformidad de la pena solicitada por el Fiscal a los límites punitivos indicados ${ }^{65}$, sin atender a si dicha sanción se ajusta a una plausible calificación jurídica de los hechos plausiblemente reconstruidos a la luz del resultado de la investigación.

\section{B. Procedimiento simplificado de resolución inmediata}

En el procedimiento simplificado la situación es aún más desmejorada, al no prever el legislador ningún examen de legalidad respecto de la pena solicitada por el Fiscal en caso de admisión de responsabilidad del imputado. Además, la doctrina no es conteste sobre la posibilidad de llevarlo a cabo ante el vacío legal, así Maturana junto a Montero ${ }^{66}$, además de Salas ${ }^{67}$ concuerdan en que no existe control jurisdiccional de ningún tipo respecto del requerimiento del Fiscal, mientras que Horvitz $^{68}$ y Chahuán ${ }^{69}$ estiman que el MP debe atenerse al principio de legalidad y objetividad, de manera que si este solicita la aplicación de una pena inferior a la que corresponde según la ley y las circunstancias del caso, el juez debiera rechazar el requerimiento sobre la base de la no concurrencia, en el caso concreto, del presupuesto de aplicación del procedimiento simplificado, ya que "la pena concreta requerida solo puede serlo la que corresponda conforme a la ley". En una posición intermedia, Sáez ${ }^{70}$ sostiene que el Fiscal debe explicar, cómo es posible, conforme a la ley, imponer la pena que para el evento de admisión de responsabilidad solicita, lo que en muchos casos le obligará a recalificar el delito, reformular los hechos, incorporar atenuantes o desechar agravantes, etc., agregando que todas esas modificaciones se harían para no ignorar "el principio de legalidad".

\section{ROL DEL OFENDIDO EN EL CONTROL JUDICIAL DE LEGALIDAD}

Si bien el control judicial que venimos tratando no depende de la iniciativa de terceros legitimados para accionar, como el ofendido, y debe materializarse ex officio por el órgano jurisdiccional, el legislador institucionaliza algunas vías formales para que el querellante active este control y consiga el rechazo de un procedimiento cuya celebración conduciría a una vulneración del principio de obligatoriedad de la acción penal como de los restantes ya estudiados, o, dentro de ese procedimiento, evitando tal resultado.

Debe darse por descontado -así también la experiencia comparada lo confirma- que la Fiscalía verá la intervención de la víctima-querellante como un impedimento para lograr

\footnotetext{
${ }_{65}$ Este parecer ha sido defendido por TAVOLARI (2005) p. 242, para quien, la pena pedida, en cuanto constituye el elemento determinante del procedimiento a seguir, es vinculante para los jueces. También, Ministerio Público con Gómez (2008).

66 Maturana y Montero (2010) T. II, p. 1083.

67 Salas (2009) pp. 231-232.

68 Horvitz (2005) T. I, p. 479.

69 Chahuán (2007) pp. 278-279.

70 SÁEZ (2007) p. 18.
} 
un acuerdo con el imputado, restándole poder de negociación. De ahí que usualmente prescindirá de ella, no obstante que el querellante deba ser citado a la audiencia de procedimiento simplificado o abreviado, de conformidad a los artículos 260, 393 y 407 del CPP, y según el artículo 109, letra d) del mismo texto tenga derecho a ser oída si lo solicitare, antes de que el Fiscal pidiere la terminación anticipada del procedimiento. Pero la víctima no solo se encontrará habitualmente con un acusador público con intereses contrarios a los que ella persigue, sino que, para que sus pretensiones tengan alguna posibilidad de fortuna, requerirá asesoría letrada, carga no baladí si se considera que por tratarse en general de delitos menores, usualmente no estará dispuesta a asumir las expensas de servicios profesionales para conseguir una pena superior a la buscada por el MP, ya que en todo caso, una condena, con indiferencia de su quantum, le facilita igualmente demandar la responsabilidad por los daños causados en sede civil (artículo 178 del Código de Procedimiento Civil).

En este asunto, debemos ser conscientes que supeditar la efectividad de los principios que peligran por un discrecional ejercicio de la acción penal por parte del MP en el marco de los procedimientos analizados, a la actividad propositiva de la víctima-querellante, hace su eficacia además de contingente, aleatoria, al pender del interés o medios de un tercero sobre el cual el Estado no tiene ningún control.

\section{Rol Del ofendido para ACtivar El CONTROL JUdicial DE LEGALidAd EN EL PROCEDIMIENTO ABREVIADO}

Conviene primero resaltar, por cuanto es ordinariamente pasado por alto en el análisis de esta materia, que el legislador reserva la aplicación del procedimiento abreviado solo para conocer y fallar, "los hechos respecto de los cuales el fiscal" requiriere la imposición de una pena, comprendiendo los hechos que fueren objeto de la acusación del querellante solo en cuanto estos no excedan aquellos, y siempre que fueren abarcados por la formalización de la investigación, de conformidad al artículo 261 letra a) del CPP. Si se admitiera como objeto del procedimiento abreviado a hechos comprendidos en la acusación particular, mas no en la acusación fiscal y, por tanto, no aceptados por el imputado, se vulnerarían los artículos $1^{\circ}$-que reconoce el derecho a un juicio oral-y 406 del CPP -que establece como presupuesto del procedimiento abreviado la expresa aceptación del imputado de los hechos materia de la acusación y de los antecedentes de la investigación que la fundaren-, preceptos que suponen necesariamente la voluntaria renuncia del acusado a defenderse de los cargos en el juicio oral como esencial justificación de su legitimidad ${ }^{71}$.

Por lo anterior, únicamente cabría admitir ampliar el objeto del procedimiento abreviado a los hechos de la acusación particular -que excedan los de la acusación del MP-,

\footnotetext{
71 Lo mismo cabe señalar si los "antecedentes" que fundan los hechos de la acusación particular no abarcados por la acusación oficial, no fueron aceptados por el imputado, ya sea porque siendo parte del cuaderno de investigación del MP, no fueron invocados por este como sostén de su acusación en la audiencia de procedimiento abreviado, o porque son elementos investigativos recabados autónomamente por el querellante y no allegados al registro de la investigación del MP. Al no haber sido aceptados por el acusado estos antecedentes, no pueden transformarse válidamente en medios probatorios que sirvan para fundar la sentencia condenatoria, pues deberán entonces someterse al debate y escrutinio oral y contradictorio propio del juicio oral, según prescriben los artículos 295 y 296 del CPP.
} 
cuando el imputado también acepte estos -y los antecedentes que los fundan-, ello, mediante analogía in bonam partem (admitida a contrario sensu, según se desprende del artículo $5^{\circ}$, inciso $2^{\circ}$, del CPP), si con ello se evita la exposición del acusado "a" y "en" un juicio oral, además de acceder a la rebaja punitiva que prevé el artículo 407 de CPP por someterse al procedimiento abreviado. Por otra parte, por esa vía se potencia aún más la intervención del querellante en el proceso como factor para controlar y moderar los excesos en que incurre el MP en las negociaciones con el imputado y su defensa.

Entonces, para examinar adecuadamente el rol del ofendido para activar el control judicial de legalidad, cabe distinguir primero si el querellante requiere en su acusación una pena superior a cinco años de presidio o reclusión menores en su grado máximo, o esa pena u otra inferior y, segundo, en cada caso, si el querellante, conforme al artículo 261 letra a) del CPP, ha ampliado la acusación extendiéndola a hechos distintos.

a) Primer supuesto: el querellante requiere en su acusación una pena superior a cinco años de presidio o reclusión menores en su grado máximo, en base a los mismos hechos de la acusación del MP, pero proponiendo una calificación jurídica de los hechos, atribuyendo una forma de participación, o señalando circunstancias modificatorias de la responsabilidad penal diferentes de las consignadas por el fiscal en su acusación.

Este caso es el expresamente reglado en los artículos 408 y 410 , inciso $2^{\circ}$, del CPP, disponiéndose que de estimar el tribunal fundada la oposición del querellante, deberá rechazar la solicitud de procedimiento abreviado y dictar el auto de apertura del juicio oral.

Ejemplo de actualización de la facultad del querellante mencionada puede advertirse en la causa RUC No 0500672825-3, del 2 Juzgado de Garantía de Santiago, en la cual el MP acusó por el delito de lesiones graves gravísimas, e invocó dos mitigantes, solicitando una pena de 3 años y un día de presidio. La parte querellante invocó cuatro agravantes, pretendiendo en consecuencia una pena de 10 años de presidio. Al estimar la sentencia de la Corte de Apelaciones de Santiago, ROL No 997-2007, de 24 de mayo de 2007 que dicha pretensión particular era fundada, conforme al artículo 414 del CPP, invalidó tanto la sentencia definitiva como la audiencia de procedimiento abreviado, ordenando la realización de la audiencia de preparación de juicio oral ${ }^{72}$.

b) Segundo supuesto: el querellante requiere en su acusación una pena superior a la pretendida por el MP, pero inferior a cinco años y un día de presidio o reclusión menores en su grado máximo, basándose en los mismos hechos de la acusación del MP, pero proponiendo una calificación jurídica de los hechos, atribuyendo una forma de participación, o señalando circunstancias modificatorias de la responsabilidad penal diferentes de las consignadas por el fiscal en su acusación

Si los hechos contenidos en la acusación particular y su correspondiente calificación no conllevan una solicitud de pena superior a los 5 años de privación de libertad, pero sí supera la sanción pretendida por el Fiscal, el querellante no puede ya oponerse a la celebra-

72 v.t. sentencias de la Corte de Apelaciones de Santiago, Atabales con Arce (2007), Rol No 2.968-2007, de 18.12.2007, y Ministerio Público con Chauán (2009). 
ción del procedimiento abreviado, atendido que el artículo 408 del CPP exige que, como consecuencia de la distinta calificación que sostiene esa parte, la pena solicitada supere el límite de 5 años de presidio o reclusión menores señalado en el artículo $406^{73}$. Empero, el Juzgado de Garantía no está vinculado a la calificación jurídica de los hechos propuesta por el MP en su acusación, y el límite de pena de la sentencia estará dado en este supuesto por la pena mayor solicitada por el querellante, según prescribe el artículo 412 del $\mathrm{CPP}^{74}$.

Algunos autores han planteado -sin eco en nuestros tribunales- que en caso de que el Fiscal y el querellante soliciten penas distintas, pero inferiores al límite de 5 años, el consentimiento del acusado deberá recaer sobre ambas acusaciones ${ }^{75}$, propuesta que se compartirá, como se dirá más adelante, solo en cuanto el relato fáctico de la acusación particular exceda el de la acusación oficial, pues de no ser así, tal aceptación no resulta pertinente, ya que el imputado solo debe consentir en "los hechos materia de la acusación" y en "los antecedentes de la investigación que la fundaren” (artículo 406, inciso $2^{\circ}$, del CPP), y no en las penas solicitadas por el Fiscal y el querellante.

c) Tercer supuesto: el querellante requiere en su acusación una pena superior a cinco años de presidio o reclusión menores en su grado máximo, en base a hechos distintos de la acusación del MP - pero comprendidos en la formalización-, que conllevan una calificación jurídica de los hechos, atribuir una forma de participación, o la concurrencia de circunstancias modificatorias de la responsabilidad penal diferentes de las consignadas por el fiscal en su acusación

En este caso, si el querellante no modifica los hechos de su acusación conforme le autoriza el artículo 407, inciso $3^{\circ}$, del CPP, retirando los que excedan la acusación del MP -esta actuación del querellante no confronta el principio de obligatoriedad de la acción penal, el que solo recae sobre el MP-, podrá dicha parte oponerse a la aplicación del procedimiento abreviado al igual que en el primer supuesto antes visto, pues el artículo 408 del CPP no excluye que la distinta calificación jurídica, participación o circunstancias modificatorias que esgrime el querellante para oponerse al procedimiento abreviado, provenga de hechos más amplios que los de la acusación oficial, de conformidad al artículo 261 letra a).

d) Cuarto supuesto: el querellante requiere en su acusación una pena de cinco años, o menos, de presidio o reclusión menores en su grado máximo, en base a hechos distintos de la acusación del MP -pero comprendidos en la formalización-, que conllevan una calificación jurídica de los hechos, atribuir una forma de participación, o la concurrencia de circunstancias modificatorias de la responsabilidad penal diferentes de las consignadas por el fiscal en su acusación

\footnotetext{
73 A juicio de NúNEz (2003) T. II, p. 442 y CERDA (2003) p. 31, una fundada petición de pena superior a los 5 años de privación de libertad es la "única causal" que puede invocar el querellante particular como fundamento de su oposición al procedimiento abreviado.

74 Así lo ha resuelto sentencias de la Corte de Apelaciones de Santiago, ROL No 2.698-2007, de 18.12.2007 y Ministerio Público con Chauán (2009).

75 Correa y Reyes (2011) p. 122.
} 
En lo que respecta a esta hipótesis, el acusador particular no puede ya oponerse a la celebración del procedimiento abreviado, atendido que el artículo 408 del CPP exige que, como consecuencia de la distinta calificación que sostiene esa parte, la pena solicitada supere el límite de 5 años de presidio o reclusión menores señalado en el artículo 406. Por otro lado, salvo expresa aceptación del imputado de los hechos de la acusación particular que excedan a la fiscal, así como de los antecedentes que fundan estos hechos distintos -conforme se explicó arriba-, aquellos no podrán ser objeto del procedimiento abreviado. En este caso entonces, el Juzgado de Garantía solo podrá desestimar el procedimiento abreviado razonando en base a los principios generales del ordenamiento penal, recurso al que escasamente suelen acudir nuestros tribunales.

\section{ROL DEL OFENDIDO PARA ACTIVAR EL CONTROL JUDICIAL DE LEGALIDAD EN EL PROCEDIMIENTO SIMPLIFICADO DE RESOLUCIÓN INMEDIATA}

Aun cuando el artículo 394 del CPP señala que al inicio de la audiencia de procedimiento simplificado, el tribunal efectuará una breve relación "del requerimiento y de la querella, en su caso", luego el artículo 395 prescribe que el tribunal preguntará al imputado si admitiere responsabilidad "en los hechos contenidos en el requerimiento" o si, por el contrario, solicitare la realización de la audiencia, es decir, la normativa procesal no solo no institucionaliza en el procedimiento simplificado una sede formal para que el actor particular manifieste su oposición al procedimiento del artículo 395 del CPP, si este pudiera conllevar la imposición de una pena máxima que no se ajusta al mérito fáctico y jurídico de la investigación, como sucede en el procedimiento abreviado, sino que tampoco se recoge en el procedimiento simplificado un precepto similar al artículo 412 del CPP, que le permita al juez fijar como pena máxima a imponer a la pretendida por el MP o el querellante.

Horvitz $^{76}$, reconociendo que las facultades del querellante se ven mermadas respecto del rito ordinario, quedándole a este solo la posibilidad de ser oído y presentar prueba en el juicio, solo da como alternativa para aquellos casos en que la pena requerida en concreto por el Fiscal se base en hechos o circunstancias que no guarden correspondencia con los antecedentes de la investigación o se valga de interpretaciones jurídicas sin asidero alguno en la ley, la jurisprudencia o la doctrina, el reclamo del querellante o la víctima ante las autoridades correspondientes por las vías que franquea la LOC del $\mathrm{MP}^{77}$.

\section{BIBLIOGRAFÍA CITADA}

Aguilera, Encarnación (1998): El "principio de consenso". La conformidad en el Proceso Penal Español (Barcelona, Cedecs, primera edición).

Alcalá-Zamora, Niceto (1962): El Allanamiento en el Proceso Penal (Buenos Aires, Ediciones Jurídicas Europa-América).

\footnotetext{
76 Horvitz (2005) T. II, pp. 480-481. Sobre el rol de la víctima y el querellante en el procedimiento simplificado, v. Letelier con Rencoret (2010) y Ministerio Público con Yáñez (2005).

77 Maturana y Montero (2010) T. II, p. 1083, confirman la imprevisión de un derecho a oposición del querellante en los términos del procedimiento abreviado.
} 
Alschuler, Albert (1968-69): “The Prosecutor's Role in Plea Bargaining”, University of Chicago Law Review vol. 36: pp. 50-112.

Armenta, Teresa (2012): Sistemas procesales penales. La justicia penal en Europa y América ¿Un camino de ida y vuelta? (Madrid, Barcelona, Buenos Aires, Marcial Pons).

Asencio, José María (2012): Derecho Procesal Penal (Valencia, Tirant lo Blanch, sexta edición).

BARONA, Silvia (1994): La conformidad en el proceso penal (Valencia, Tirant lo Blanch).

BeCKer, Howard (2009): Outsiders: hacia una sociología de la desviación (Buenos Aires, Siglo Veintiuno).

Bullemore, Vivian y Mackinnon, John (2005): Curso de Derecho Penal. Parte General (Santiago, LexisNexis, T.I).

CERDA, Rodrigo (2003): Etapa intermedia, juicio oral y recursos (Santiago, Librotecnia).

Cerda, Rodrigo y Hermosilla, Francisco (2003): El procedimiento abreviado (Nuevo sistema procesal penal) (Santiago, Metropolitana).

Cerda, Rodrigo y Hermosilla, Francisco (2006): El Código Procesal Penal. Comentarios, Concordancias y Jurisprudencia (Santiago, Librotecnia, segunda edición).

Chahuán, Sabas (2007): Manual del Nuevo Procedimiento Penal (Santiago, LexisNexis, tercera edición).

Conde-Pumpido, Cándido (1989): "El principio de oportunidad reglada: su posible incorporación al sistema del proceso penal español”, en VV.AA. La Reforma del Proceso Penal. II Congreso de Derecho Procesal de Castilla y León (Madrid, Ministerio de Justicia) pp. 287-308.

Correa, Carlos y Reyes, Mauricio (2011): El procedimiento abreviado y la justicia criminal negociada. Derecho chileno y comparado (Santiago, Editorial Jurídica de Chile).

Cury, Enrique (2000): "La reforma procesal penal y la legislación penal", en VV.AA. El Nuevo Proceso Penal Chileno (Universidad de Concepción, Facultad de Ciencias Jurídicas y Sociales, Dept. de Derecho Procesal) pp. 297-305.

Cury, Enrique (2005): Derecho Penal. Parte General (Santiago, Universidad Católica de Chile, séptima edición).

DAmASKA, Mirjan (2010): "Negotiated Justice in International Criminal Courts", en STEPHEN, T. (ed.) World plea bargaining. Consensual procedures and the avoidance of the full criminal trial (Durham, Carolina Academic Press).

De Diego, Luis Alfredo (1997): La conformidad del acusado (Valencia, Tirant lo Blanch).

Del Río, Carlos (2008): "El principio del consenso de las partes en el proceso penal y enjuiciamiento jurisdiccional: aclaraciones conceptuales necesarias”, Revista Chilena de Derecho. vol. 35, No 1: pp. 157-182.

Del Río, Carlos (2009a): Los poderes de decisión del juez penal. Principio acusatorio y determinadas garantías procesales (el deber de correlación) (Santiago, Jurídica de Chile).

Del Río, Carlos (2009b): Proceso penal, consenso de las partes y enjuiciamiento jurisdiccional (Santiago, Librotecnia).

Del Río, Carlos (2010): “Dos formas discutibles de poner en duda el carácter cognoscitivo de la aplicación judicial del derecho penal: El principio del consenso y la garantía de la 
no agravación punitiva", Revista de Derecho de la Pontifica Universidad Católica de Valparaíso. No 34: pp. 349-383.

Díez-Picazo, Luis María (2000): El poder de acusar, Ministerio Fiscal y Constitucionalismo (Barcelona: Ariel).

Duce, Mauricio y Riego, Cristian (2002): Introducción al Nuevo Sistema Procesal Penal (Santiago, Universidad Diego Portales, Escuela de Derecho).

Etcheberry, Alfredo (2001): Derecho Penal. Parte General (Santiago, Editorial Jurídica de Chile, T. II, tercera edición).

Falcone, Diego (2005): "La absolución en el procedimiento abreviado", Revista de Derecho de la Pontificia Universidad Católica de Valparaíso, XXVI: pp. 363-378.

Ferrajoli, Luigi (2001): Derecho y razón. Teoría del garantismo penal (Madrid, Trotta, quinta edición).

Garrido, Mario (2001): Derecho Penal. Parte General (Santiago, Editorial Jurídica de Chile, T.I).

Gimeno, Vicente (2012): Derecho Procesal Penal (España, Civitas).

Goldstein, Abraham (1981) The passive judiciary. Prosecutorial discretion and the guilty plea (Louisiana State University Press).

Hassemer, Winfried (1984): Fundamentos del Derecho Penal (trad. F. Muñoz Conde y L. Arroyo Zapatero, Barcelona, Bosch).

Horvitz, María Inés y López, Julián (2005): Derecho Procesal Penal Chileno (Santiago, Editorial Jurídica de Chile, T. I y II).

Jescheck, Hans-Heinrich y Weigend, Thomas (2002): Tratado de Derecho Penal. Parte General (trad. M. Olmedo, Granada, Comares, quinta edición).

Maier, Julio (1989): Derecho Procesal Penal Argentino (Buenos Aires, Hammurabi, T. I, vol. B.)

MañAlich, Juan Pablo (2010): “¿Discrecionalidad judicial en la determinación de la pena en caso de concurrencia de circunstancias atenuantes de la responsabilidad penal?", en Centro de Documentación Defensoría Penal Pública. Informes en Derecho, No 7: pp. 41-66.

Marafioti, Luca (2008): "Italian Criminal Procedure: A system Caught Between Two Traditions", en Jackson, J., LÁnger, M., Tillers, P. Crime, Procedure and Evidence in a Comparative International Context. Essays in Honour of Professor Mirjan Damaska (Portland, Hart Publishing) pp. 81-98.

Martín, José (2013): "Algunas manifestaciones de la aproximación entre el proceso penal y el proceso civil”, en ARMENTA, Teresa (Coord.) La convergencia entre proceso civil y penal ¿Una dirección adecuada? (Madrid, Marcial Pons).

Maturana, Cristián y Montero, Raúl (2010): Derecho Procesal Penal (Santiago, LegalPublishing, T. I y II).

Matus, Jean Pierre y Van weezel, Alex (2003): “Artículos 50 a 73”, en Politoff, Sergio y Ortiz, Luis. (Dir.) Texto y comentario del Código Penal chileno (Santiago, Editorial Jurídica de Chile) pp. 323-382.

Maurach, Reinhart, Gössel, Karl, y Zipf, Heinz (1994): Derecho Penal. Parte General (trad. J. Bofill G. y E. Aimone G., Buenos Aires, Astrea).

Mcdonald, William (1986-87): "Judicial Supervision of the Guilty Plea Process: A Study in Six Jurisdictions”, Judicature, vol. 70: pp. 203-215. 
Medina, Gonzalo (2009): "Sobre la determinación de pena y el recurso de nulidad en la ley 20.084 sobre responsabilidad penal adolescente”, Revista de Estudios de la Justicia, No 11: pp. 201-234.

Mera Figueroa, Jorge (2004): “Discrecionalidad del Ministerio Público, calificación jurídica y control judicial", en Informe de Investigación $N^{\circ} 1$ al 15, 1999-2003 (Santiago, Centro de Investigaciones Jurídicas. Facultad de Derecho Universidad Diego Portales).

Montero, Juan et al. (2013): Derecho Jurisdiccional, Proceso Penal (Barcelona, Bosch).

Morales, Ana, Muñoz, Nicolás, Welsch, Gherman, y Fábrega, Jorge (2012): La Reincidencia en el Sistema Penitenciario Chileno (Santiago, Fundación Paz Ciudadana).

Novon, Eduardo (2005): Curso de Derecho Penal Chileno. Parte General (Santiago, Editorial Jurídica de Chile, T. II, tercera edición).

Núñez, Juan Cristóbal (2003): Tratado del Proceso Penal y del Juicio Oral (Santiago, Editorial Jurídica de Chile).

Oberg, Héctor (2000): "Justicia penal negociada", en VV.AA. El Nuevo Proceso Penal Chileno (Universidad de Concepción, Facultad de Ciencias Jurídicas y Sociales, Dept. de Derecho Procesal) pp. 157-166.

Pecchi, Carlos (2000) “El procedimiento abreviado en el nuevo Código Procesal Penal”, en VV.AA. El Nuevo Proceso Penal Chileno (Universidad de Concepción, Facultad de Ciencias Jurídicas y Sociales, Dept. de Derecho Procesal) pp. 167-183.

Piedrabuena, Guillermo (2000): Introducción a la Reforma Procesal Penal (Santiago, Fallos del Mes).

Pizzi, William (2004): Juicios y mentiras (trad. C. F. Gallardo, Madrid, Tecnos).

Politoff, Sergio, Matus, Jean Pierre y Ramírez, María Cecilia (2004): Lecciones de derecho penal chileno. Parte general (Santiago, Editorial Jurídica de Chile, segunda edición).

Quintero, Gonzalo, Morales, Fermín y Prats, Miguel (1996): Curso de Derecho Penal. Parte General (Acorde al Nuevo Código Penal de 1995) (Barcelona, Cedecs).

Rodríguez, Nicolás (1997): La justicia penal negociada. Experiencias de derecho comparado (Salamanca, Ediciones Universidad Salamanca).

Rudnick, Carolina (2007): La compensación racional de circunstancias modificatorias en la determinación judicial de la pena (Santiago, LexisNexis, segunda edición).

Ruiz, Enrique (1994): El Principio Acusatorio y su Proyección en la Doctrina Jurisprudencial del Tribunal Constitucional y Tribunal Supremo (Madrid, Actualidad Editorial).

SÁEZ, Jorge (2007): "Controles judiciales en los procedimientos convencionales", Revista procesal penal, No 55: pp. 9-25.

Salas, Jaime (2009): Problemas del proceso penal (Santiago, Librotecnia).

SAlinero, Sebastián (2012): “¡Por qué aumenta la población penal en Chile? Un estudio criminológico longitudinal”, Revista Ius et Praxis, año 18, No 1: pp. 113-150.

SCHÜNEMANN, Bernd (2002): “¿Crisis del procedimiento penal? (¿marcha triunfal del procedimiento penal americano en el mundo?)”, en Temas actuales y permanentes del Derecho penal después del milenio (Madrid, Tecnos) pp. 288-302.

Tavolari, Raúl (2005): Instituciones del Nuevo Proceso Penal. Cuestiones y Casos (Santiago, Editorial Jurídica de Chile). 
Van Weezel, Álex (1997): "Compensación racional de atenuantes y agravantes en la medición judicial de la pena”, Revista Chilena de Derecho, vol. 24, No 3: pp. 459-502.

Van Weezel, Álex (2001): "Determinación de la Pena Exacta: El Artículo 69 del Código Penal”, Ius et Praxis, Año 7, No 2: pp. 401-407.

\section{NORMAS CITADAS}

Código de Procedimiento Penal

Código Procesal Penal

Código Penal

Código Orgánico de Tribunales

Código de Procedimiento Civil

Constitución Política de la República

Ley No 18.216, de 14 de mayo de 1983, Establece penas que indica como sustitutivas a las penas privativas o restrictivas de libertad.

Ley No 18.290, de 7 de noviembre de 2009, Ley del Tránsito.

Ley No 20.074, de 14 de noviembre de 2005, modifica los Códigos Procesal Penal y Penal.

\section{JURISPRUDENCIA CITADA}

Ministerio Público con Bustamante (2009): Juzgado de Garantía de San Pedro de la Paz, 6 de agosto del año 2008.

Ministerio Público con Madariaga (2009): Juzgado de Garantía de Coquimbo, 2 de octubre del año 2010.

García con Carrasco (2013): 2o Juzgado de Garantía de Santiago, 30 de enero del año 2013.

Ministerio Público con Paredes (2012): Corte de Apelaciones de Temuco, ROL No 452012, de 30 de enero del año 2012.

Ministerio Público con Sivoli (2006): Corte de Apelaciones de Santiago, ROL No 1.0832006, de 6 de julio del año 2006.

Ministerio Público con Varas (2008): Corte de Apelaciones de Antofagasta, ROL No 7-2008, de 6 de febrero del año 2008.

LETELIER CON RENCORET (2010): Corte Suprema, ROL No 10.150-2010, de 28 de marzo del año 2011.

Ministerio Público con Vallade (2009): 2o Juzgado de Garantía de Santiago, RUC No $1100926057-0$, de 26 de julio del año 2012.

Ministerio Público con Varas (2009): del Juzgado de Garantía de Valdivia, RUC No 1100289676-3, de 12 de septiembre del año 2011.

Ministerio Público con Valenzuela (2009): Juzgado de Garantía de Los Ángeles, RUC No 1201140366-0, de 16 de noviembre de 2012.

Ministerio Público con Muñoz (2007): Juzgado de Garantía de Puerto Montt, RUC No 0600533365-0, de 5 de marzo del año 2007. 
Ministerio Público con Campos (2011): 6o Juzgado de Garantía de Santiago, RUC No 1100917253-1, de 24 de octubre de 2012.

Ministerio Público con Zapata (2012): Juzgado de Garantía de Coquimbo, RUC No 1000055500-8, con fecha 19 de diciembre del año 2012.

Ministerio Público con Contreras (2012): Juzgado de Garantía de Coquimbo, RUC No 1200135493-9, de 30 de marzo del año 2012.

BLANCO CON ARGUEDAS (2012): Juzgado de Garantía de Coquimbo, RUC No 1200462700 6, de 27.07.2012

HERNÁNDEZ CON ALARCÓN (2012): Juzgado de Letras, Garantías y Familia de Quirihue; RUC No 1200243839-7, de 16 de noviembre del año 2012.

Cifuentes CON YÁÑEz (2012): 2o Juzgado de Garantía de Santiago, RUC No 0900255837 -

5 , de 27 de enero del año 2012.

Ministerio Público con GuZmán (2012): Juzgado de Garantía de Lautaro, RUC No $1210014562-4$, de 14 de agosto del año 2012.

Ministerio Público con GonzÁlez (2010): Juzgado de Garantía de Puerto Varas, RUC No 0910029611-7, de 4 de febrero del año 2010.

TORRES CON OSSANDÓN (2011): Juzgado de Garantía de Coquimbo, RUC No $1100693644-$ 1 , de 3 de diciembre del año 2011.

Ministerio Público con Varas (2008): Juzgado de Garantía de Santa Cruz, RUC No 0800592523-2, de 15 de julio del año 2008.

VillanUeVA CON SÁNCHEZ (2010): Juzgado de Garantía de Coquimbo, RUC No 1000241793-1, de 19 de octubre del año 2010.

Ministerio Público con Ardiles (2012): Juzgado de Garantía de Coquimbo, RUC No $1100172703-8$, de 4 de enero del año 2012.

Ministerio Público con González (2012): Juzgado de Garantía de Punta Arenas, RUC No 1200462142-3, de 21 de agosto del año 2012.

Ministerio Público con Vergara (2006): Juzgado de Garantía de Puerto Montt, RUC No 0600479969-9, de 12 de julio del año 2006.

Ministerio Público con Galarce (2012): Juzgado de Garantía de Antofagasta, RUC No 1200253536-8, de 17 de agosto del año 2012.

Ministerio Público con Espina (2013): Juzgado de Garantía de Melipilla, RUC No 1200043071-2, de 23 de enero del año 2013.

VÁSQUEZ CON ACUÑA (2012): Juzgado de Garantía de Curacaví, RUC No 1101256974-4, de 27 de noviembre del año 2012.

Ministerio Público con NúNez (2010): Juzgado de Garantía de Coquimbo, RUC No 1001051563-2, de 6 de diciembre del año 2011.

Riquelme CON Ramírez (2012): del Juzgado de Garantía de Villa Alemana, RUC No 1101198099-8, de 2 de octubre del año 2012.

Ministerio Público con Medina (2008): Juzgado de Garantía de Santa Cruz, RUC No 0700606928-7, de 1 de marzo del año 2008.

Ministerio Público con Águila (2010): Juzgado de Garantía de Osorno, RUC No 1000459761-9, de 27 de septiembre del año 2010. 
Ministerio Público con Mejías (2010): Juzgado de Garantía de Linares, RUC No 0700267260-4, de 26 de diciembre del año 2010.

Ministerio Público con RoA (2013): Juzgado de Garantía de Linares, RUC No 1000966124-2, de 22 de enero del año 2013.

Ministerio Público con Alonso (2012): Juzgado de Garantía de Punta Arenas, RUC No 1101033498-7, de 21 de enero del año 2012.

Ministerio Público con Figueroa (2009): RUC No 0801059594-1, de 23 de enero del año 2009.

Ministerio Público con Pardo (2012): Juzgado de Garantía de Coquimbo RUC No 0800655654-0, de 29 de mayo del año 2012.

Ministerio Público con Damanes (2008): Juzgado de Garantía de San Antonio, RUC No 0600037854-0, de 16 de enero del año 2008.

Ministerio Público con Ruiz (2009): Juzgado de Garantía de San Vicente, RUC No 0800964958-2, de 25 de septiembre del año 2009.

Ministerio Público con FerRada (2013): Juzgado de Garantía de Linares, RUC No 1200229891-9, de 23 de enero del año 2013.

ABALOS CON RENCORET (2010): $4^{\circ}$ Juzgado de Garantía de Santiago, RUC No 1000764947-4.

Ministerio Público con Barahona (2006): Corte Suprema, ROL No 2.618-2003, de 30 de marzo del año 2006.

HERRERA CON ROMERo (2006): Corte de Apelaciones de Valparaíso, ROL No 03-2006, de 6 de febrero del año 2006.

VALENCIA CON ABARCA (2006): Corte de Apelaciones de Santiago, ROL No 931-2006, de 9 de junio del año 2006.

Ministerio Público con Caris (2013): RUC No 1300096777-1, de 27 de enero del año 2013.

SALINAS CON CARRASCO (2013): $9^{\circ}$ Juzgado de Garantía de Santiago RUC No $1200764804-$ 7, de 27 de enero del año 2013.

SÁNCHEZ CON MORENO (2013): $9^{\circ}$ Juzgado de Garantía de Santiago RUC No 1000549851 7, de 27 de enero del año 2013.

Carabineros de Chile con Araya (2013): $6^{\circ}$ Juzgado de Garantía de Santiago, RUC No 0900607925-0, de 30 de enero del año 2013.

Ministerio Público con Opazo (2009): Juzgado de Garantía de Colina, RUC No 1201272323-5, de 24 de diciembre del año 2012.

CERDA CON CÁCERES (2013): $14^{\circ}$ Juzgado de Garantía de Santiago, RUC No 1201118079-3, de 29 de enero del año 2013.

TAGLE CON FUSTER (2010): $4^{\circ}$ Juzgado de Garantía de Santiago, RUC No 0700454268-6, de 15 de enero del año 2010.

Ministerio Público con Werner (2006): Juzgado de Garantía de Illapel, RUC No 0400082703-2, el 30 de agosto del año 2006.

Ministerio Público con Allende (2006): Corte de Apelaciones de Santiago, ROL No 1.839-2006, de 20 de octubre del 2006.

Ministerio Público con Vicencio (2004): Corte Suprema, ROL No 4.180-2004, de 25 de enero del año 2005. 
Ministerio Público con Marín (2004): Corte de Apelaciones de Rancagua, ROL No 372004, de 23 de junio del año 2004.

Ministerio Público con Gómez (2008): Corte de Apelaciones de Rancagua, ROL No 1862008, de 2 de junio del año 2008.

Atabales con ARCE (2007): Corte de Apelaciones de Santiago, ROL No 997-2007, de 24 de mayo del año 2007.

Ministerio Público con Chahuán (2009): Corte de Apelaciones de Santiago, ROL No 1.611-2009, del 10 de septiembre del año 2009.

Ministerio Público con YÁÑez (2009): Corte Suprema, ROL No 2.693-2005, de 3 de agosto del año 2005. 
